\title{
Validating the identity of Paramoeba invadens, the causative agent of recurrent mass mortality of sea urchins in Nova Scotia, Canada
}

\author{
Colette J. Feehan ${ }^{1, *, * *}$, Jessica Johnson-Mackinnon ${ }^{1, * *}$, Robert E. Scheibling ${ }^{1}$, \\ Jean-Sébastien Lauzon-Guay ${ }^{2}$, Alastair G. B. Simpson ${ }^{1}$ \\ ${ }^{1}$ Biology Department, Dalhousie University, Halifax, Nova Scotia B3H 4R2, Canada \\ ${ }^{2}$ Fisheries and Oceans Canada, Institut Maurice-Lamontagne, Mont-Joli, Quebec G5H 3Z4, Canada
}

\begin{abstract}
Green sea urchins Strongylocentrotus droebachiensis along the coast of Nova Scotia Canada, suffer mass mortalities from infection by the pathogenic amoeba Paramoeba invadens Jones, 1985. It has been speculated that $P$. invadens could be a form of Neoparamoeba pemaquidensis, a species associated with disease in $S$. droebachiensis and lobsters in the northeast USA. During a disease outbreak in fall 2011, we isolated amoebae from moribund urchins collected from 4 locations along $\sim 200 \mathrm{~km}$ of coastline. In laboratory infection trials, we found that timing and rate of morbidity corresponded to that of similar experiments conducted in the early 1980s, when $P$. invadens was first identified. All isolates had a similar size and morphology to the original description, including an absence of microscales. Sequences of nuclear SSU rDNA show that disease was caused by one 'species' of amoeba across the range sampled. Phylogenetic analyses prove that $P$. invadens is not conspecific with $N$. pemaquidensis, but is a distinct species most closely related to $N$. branchiphila, a suspected pathogen of sea urchins Diadema aff. antillarum in the Canary Islands, Spain. Morphology and closest phylogenetic affinities suggest that $P$. invadens would be assignable to the genus Neoparamoeba; however, nuclear SSU rDNA trees show that Neoparamoeba and Paramoeba are phylogenetically inseparable. Therefore, we treat Neoparamoeba as a junior synonym of Paramoeba, with $P$. invadens retaining that name, and $N$. pemaquidensis and $N$. aestuarina reverting to their original names ( $P$. pemaquidensis and $P$. aestuarina), and with new combinations for $N$. branchiphila Dykova et al., 2005, and N. perurans Young et al., 2007, namely P. branchiphila comb. nov. and P. perurans comb. nov.
\end{abstract}

KEY WORDS: Paramoeba invadens - Neoparamoeba - Paramoebiasis - Sea urchin · Parasite · SSU rDNA · Disease

\section{INTRODUCTION}

In marine ecosystems, the identity and source of the causative agent(s) of epizootics are often unresolved, due in part to difficulties in detecting potential pathogens in host tissues or the surrounding environment. For example, the pathogenic agent that decimated the sea urchin Diadema antillarum throughout its geographic range in the Caribbean in 1983, causing a phase shift from corals to fleshy macroalgae on many reefs, remains unidentified (Lessios 1988). Similarly, causal agents have only been identified for 6 of 19 common coral diseases, which also have had important ecosystem-level effects (Harvell et al. 2007). Even when agents are identified, difficulties with reliably identifying pathogens to the 'species' level can result in incorrect assumptions about the host-specificity or generality of the agent (Young et al. 2008, Crosbie et al. 2012). In recent years, genetic tools have become a reliable 
means of precisely identifying pathogens associated with diseases of marine organisms (e.g. Senapin et al. 2007, Young et al. 2007, Dyková et al. 2011).

Along the Atlantic Coast of Nova Scotia, Canada, recurrent mass mortalities of the green sea urchin Strongylocentrotus droebachiensis drive transitions between the alternative community states in the rocky subtidal zone, viz. kelp beds and sea urchin barrens (Miller 1985, Scheibling 1986). These disease outbreaks are associated with tropical storm and hurricane activity and warm sea temperatures, and have increased in frequency over the past 3 decades (Scheibling \& Hennigar 1997, Scheibling \& Lauzon-Guay 2010). The pathogenic agent, an amoeba isolated from moribund urchins following a disease outbreak in 1983, was described as a new species, Paramoeba invadens (Jones 1985). The pathology of paramoebiasis in sea urchins has been characterized and Koch's postulates confirmed (Jones et al. 1985, Jones \& Scheibling 1985). Paramoebiasis is highly host-specific and temperaturedependent (Scheibling \& Stephenson 1984, Jellett et al. 1988, Jellett \& Scheibling 1988a), and only affects sea urchins in shallow water $(<25 \mathrm{~m}$ depth) in the summer or early fall when sea temperatures are above $\sim 10^{\circ} \mathrm{C}$, the thermal threshold for disease propagation (Scheibling 1984, 1988, Brady \& Scheibling 2005, Feehan et al. 2012). However, the source population(s) of the pathogenic amoeba and mechanism of spread along the coast of Nova Scotia remain poorly understood.

Organisms assigned to the genera Paramoeba and Neoparamoeba are dactylopodid amoebozoan amoebae that carry a characteristic perinuclear body known as the parasome (Page 1987, Kudryavtsev et al. 2011). The parasome is actually a eukaryotic endosymbiont (specifically a kinetoplastid), leading to its alternative moniker of 'Perkinsela-like organism', or 'PLO'. The genera are nominally distinguished primarily by the presence in Paramoeba of surface microscales (Page 1987), which are organic boat-shaped surface structures several hundred nanometers across that are readily observed by electron microscopy (Kudryavtsev et al. 2011). Paramoeba and Neoparamoeba are ubiquitous in temperate marine environments, and most species are free-living (Page 1970, Jones 1985, Dyková et al. 2005, Kudryavtsev et al. 2011). Nonetheless, they also act as facultative parasites in a variety of marine species aside from sea urchins, including Atlantic salmon Salmo salar in aquaculture, and decapod crustaceans along the eastern seaboard of the USA (Table 1). Analysis of smallsubunit (SSU) ribosomal DNA (rDNA) is an effective method used to unambiguously discriminate between closely related species of Paramoeba and Neoparamoeba (Table 1). No genetic information has been available on $P$. invadens, however, and in its absence it has been suggested that this species could be a form of $N$. pemaquidensis (basionym P. pemaquidensis), a morphologically similar amoeba associated with diseases of both lobsters Homarus americanus and sea urchins Strongylocentrotus droebachiensis in the northeastern USA (Mullen et al. 2005).

The issue of whether Paramoeba invadens exists as a distinct species has obvious implications for understanding the transmission of this disease within the environment, its geographic extent and the nature of sources for new outbreaks. The objectives of our study were (1) to confirm that the amoebae infecting sea urchins in Nova Scotia in fall 2011 were functionally and morphologically similar to the original $P$. invadens isolated from diseased sea urchins in the early 1980s, and (2) to test whether $P$. invadens is a distinct species using SSU rDNA data, and if so, determine its phylogenetic affinities and appropriate systematic designation. We find that $P$. invadens is a distinct Neoparamoeba-like species (i.e. without microscales) most closely related to an organism originally described as $N$. branchiphila, but in the process confirm that Paramoeba and Neoparamoeba cannot be reconciled as distinct clades in nuclear SSU rDNA phylogenies. Rather than assign $P$. invadens to Neoparamoeba, we conclude that Neoparamoeba must be regarded as a synonym of Paramoeba, and that all Neoparamoeba species be treated (again) as species of Paramoeba.

\section{MATERIALS AND METHODS}

\section{Collection of infected sea urchins}

Following the passage of Hurricane Katia on 9 September 2011, SCUBA divers observed a mass mortality of sea urchins at $8 \mathrm{~m}$ depth in barrens at Splitnose Point, Nova Scotia, and in experimental cages in kelp beds within and immediately outside St. Margarets Bay, 40 km west-southwest of Splitnose Point (Fig. 1). Caged sea urchins had been transplanted to St. Margarets Bay from Splitnose Point on 6 August 2011 as part of an ongoing experiment investigating the association between hurricanes and disease outbreaks (Feehan et al. 2012). Moribund sea urchins, with overt signs of paramoebiasis, including loss of attachment to the substrate, disheveled spines, shriveled and non-functional tube feet and a gaping peri- 


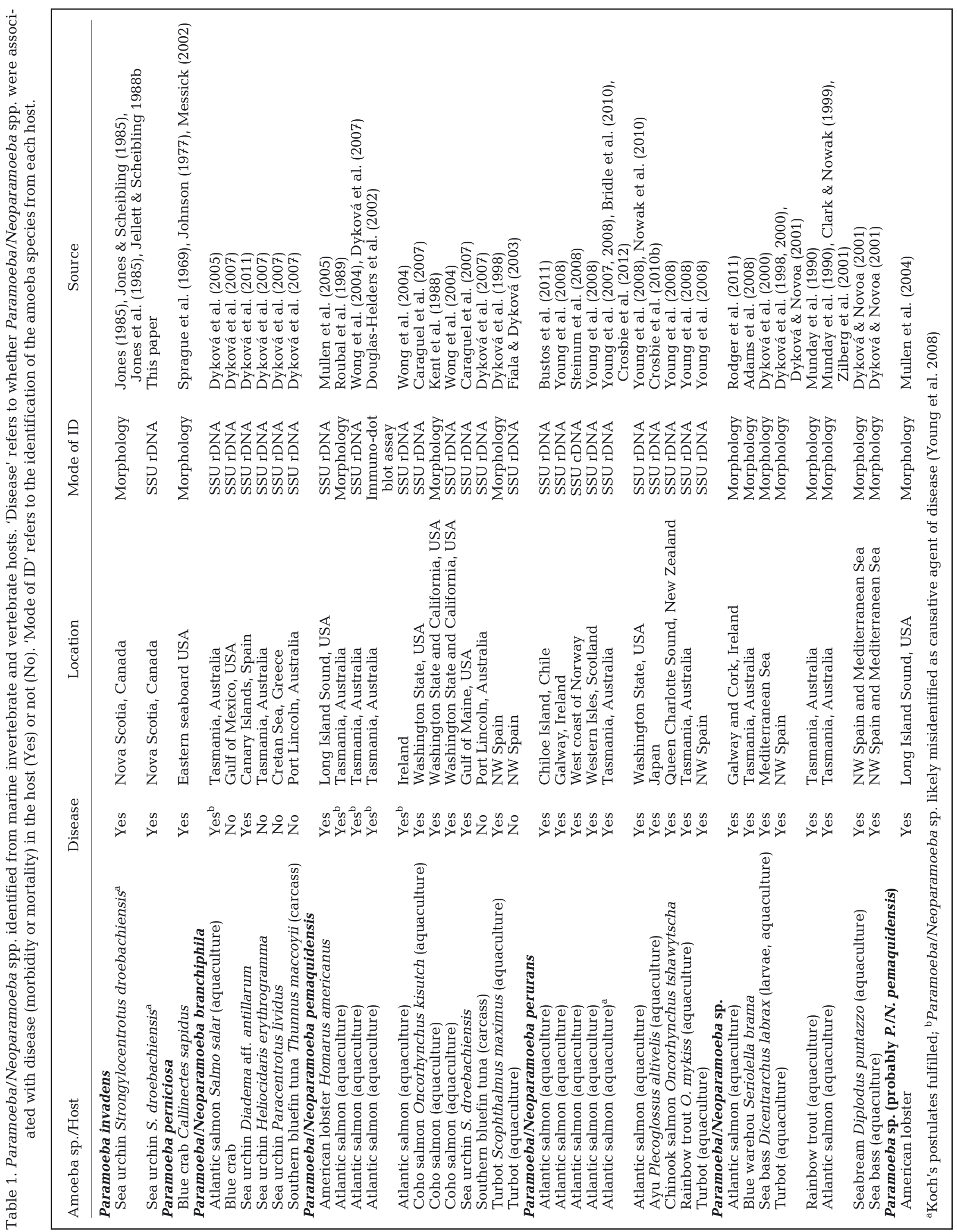




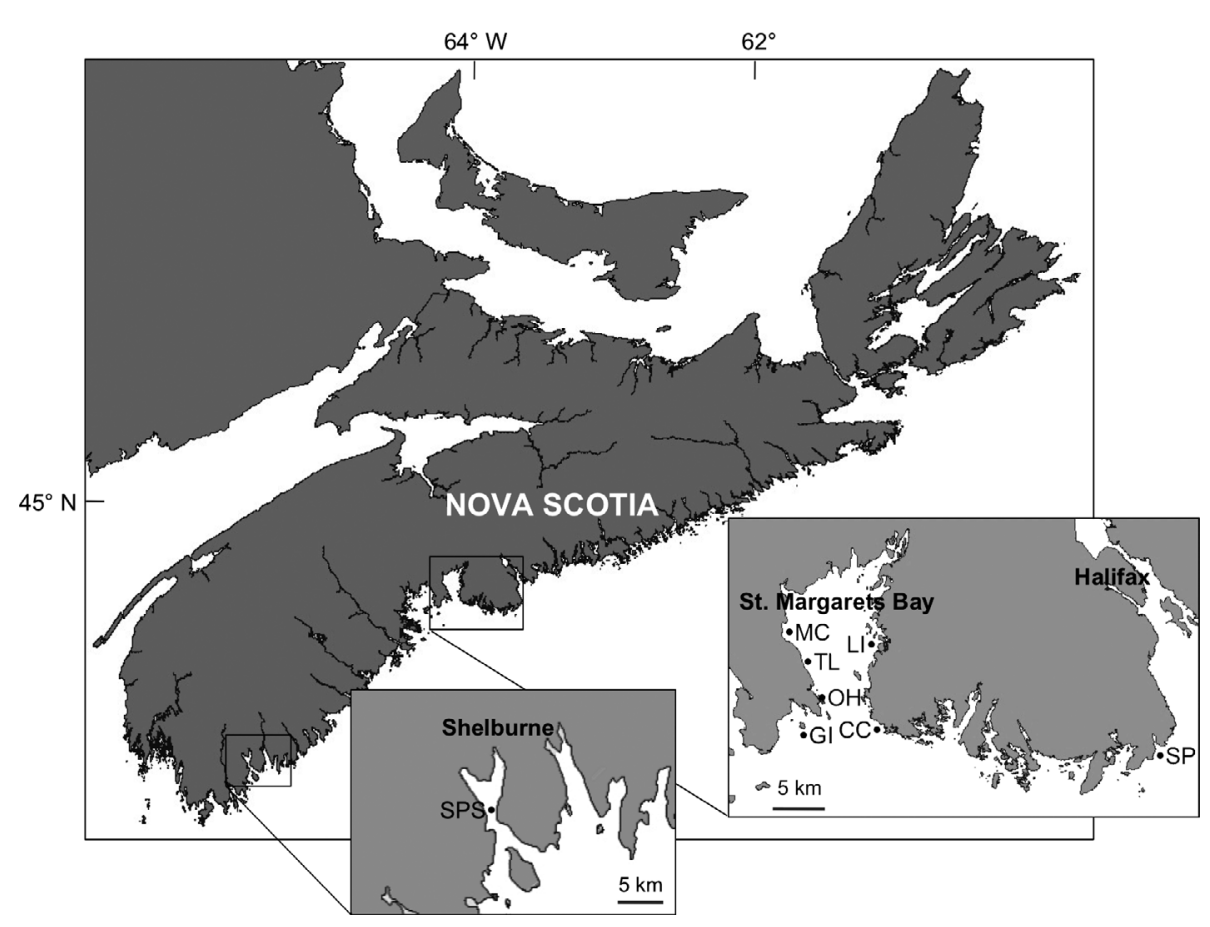

Fig. 1. Collection sites of Strongylocentrotus droebachiensis along the coast of Nova Scotia, Canada. The insets show 1 site near Shelburne, Nova Scotia (SPS: Sandy Point, Shelburne), 5 sea urchin caging sites within and immediately outside of St. Margarets Bay (MC: Mill Cove; TL: The Lodge; GI: Gravel Island; CC: Cranberry Cove; LI: Luke Island), 1 site at the mouth of St. Margarets Bay (OH: Owls Head) and 1 site along a headland near the mouth of Halifax Harbour (SP: Splitnose Point) stome (Scheibling \& Stephenson 1984), were collected by divers from cages in St. Margarets Bay and from barrens at Splitnose Point on 29 September and 9 November 2011, respectively.

To determine the extent of the disease outbreak, and to obtain additional isolates of amoebae, we acquired sea urchins from 2 other sites along the coast of Nova Scotia (Fig. 1). On 19 October 2011, we collected sea urchins in baited traps from a sedimentary basin at $60 \mathrm{~m}$ depth off Owl's Head, near the mouth of St. Margarets Bay. On 22 November 2011, we acquired sea urchins that had been collected by divers from barrens at Sandy Point, Shelburne County, $200 \mathrm{~km}$ southwest of St. Margarets Bay (purchased from C. Hopkins, Barrington Passage, Nova Scotia). At both sites, bottom temperature at the time of collection was below the thermal threshold for paramoebiasis $\left(\sim 5^{\circ} \mathrm{C}\right.$ at $60 \mathrm{~m}$ in St. Margarets Bay, K. Filbee-Dexter \& R. E. Scheibling unpubl. data $\sim 9^{\circ} \mathrm{C}$ at $8 \mathrm{~m}$ depth at Sandy Point, C. Hopkins pers. comm.). Both groups of sea urchins developed signs of paramoebiasis after they were maintained in flowing seawater aquaria at $16^{\circ} \mathrm{C}$ in the laboratory, suggesting that the pathogenic agent was present at these sites but suppressed by low temperatures in the field. Observations made by local fishers of moribund urchins at Sandy Point, and mass mortality of sea urchins at nearby sites (Barrington Bay and Lockport, Shelburne County) in October and November 2011 (C. Hopkins pers. comm.) provide corroborating evidence that paramoebiasis was present at this site.
All sea urchins were transported in chilled plastic bins to the Aquatron at Dalhousie University, Halifax, Nova Scotia, within $6 \mathrm{~h}$ of collection. Sea urchins collected from Splitnose Point on 5 August 2011 (prior to disease outbreak), and maintained at $16^{\circ} \mathrm{C}$ in the laboratory from 19 September to 24 November did not exhibit signs of morbidity, indicating that a pathogen was not present in the seawater system of the Aquatron.

\section{Polyxenic and monoxenic culturing of amoebae}

Amoebae were isolated from the radial nerve of moribund sea urchins obtained either directly from the field (Splitnose Point at $8 \mathrm{~m}$ depth: isolate SP; St. Margarets Bay cages at $8 \mathrm{~m}$ : isolate SMB-8) or from thermal induction experiments (St. Margarets Bay at $60 \mathrm{~m}$ : isolate SMB-60; Sandy Point, Shelburne at $8 \mathrm{~m}$ : isolate SPS), using the methods of Jones \& Scheibling (1985). Briefly, strips of radial nerve with associated radial water-vascular canal $(0.5 \mathrm{~cm}$ length) were excised from the oral region of sea urchins and placed on $0.6 \%$ non-nutrient $(\mathrm{NN})$ marine agar (salinity 35). After $1 \mathrm{wk}$, amoebae had moved out of the tissues and into the semi-solid agar. Amoebae were subcultured by removing a $1 \mathrm{~cm}^{2}$ piece of $0.6 \%$ agar onto $1.2 \% \mathrm{NN}$ agar with a $200 \mathrm{\mu l}$ liquid overlay containing bacterial prey (Escherichia coli in sterile seawater). The liquid overlay was prepared by inoculating $3 \mathrm{ml}$ of lyso- 
geny broth (LB) with E. coli at $37^{\circ} \mathrm{C}$ for $24 \mathrm{~h}$, centrifuging the liquid culture $(3000 \times g, 5 \mathrm{~min})$, and replacing the supernatant and resuspending the pellet in $3 \mathrm{ml}$ of seawater.

Monoxenic cultures of amoebae were obtained using the methods of Jellett \& Scheibling (1988b). A $1 \mathrm{~cm}^{2}$ piece of polyxenic culture of amoebae was removed to $1 \mathrm{ml}$ of antibiotic solution (10 $000 \mathrm{UI}$ penicillin, $10000 \mu \mathrm{g}$ streptomycin) for $5 \mathrm{~h}$, and then plated onto $1.2 \% \mathrm{NN}$ agar with liquid overlay (as described above). Amoebae in both monoxenic and polyxenic culture were maintained at $18^{\circ} \mathrm{C}$ and subcultured onto $1.2 \% \mathrm{NN}$ agar with liquid overlay at 1 to $2 \mathrm{wk}$ intervals.

\section{Laboratory experiments}

We conducted 2 types of experiments (below) to test whether the dynamics of paramoebiasis caused by amoebae isolated from moribund sea urchins in fall 2011 were consistent with those observed in similar experiments since the early 1980s and attributed to Paramoeba invadens (Scheibling \& Stephenson 1984, Jones \& Scheibling 1985, Jellett \& Scheibling 1988b, Scheibling et al. 2010, Feehan et al. 2012). All experiments were conducted in 471 glass aquaria supplied with oxygenated temperature-controlled flowing seawater $\left(\sim 31 \mathrm{~min}^{-1}\right)$ in a quarantine laboratory of the Aquatron at Dalhousie University.

Table 2. Strongylocentrotus droebachiensis. Injection experiments to measure rate of morbidity of sea urchins injected with Paramoeba invadens. 'Urchin source' is the collection site for healthy experimental sea urchins (SP: Splitnose Point, Nova Scotia; GSL: Gulf of St. Lawrence, Quebec; NS: unknown sites along the coast of Nova Scotia). 'Amoeba source' is the collection site (and depth in $\mathrm{m}$ ) of moribund sea urchins from which amoebae were isolated (SMB: St. Margarets Bay, Nova Scotia; SPS: Sandy Point, Shelburne, Nova Scotia). 'Culture age' refers to the start of the experiment. Dose is the estimated mean $( \pm \mathrm{SE})$ number of amoebae $\mathrm{ml}^{-1}$ injected into sea urchins. $\mathrm{n}$ is the number of urchins per aquarium. ND: no data available

\begin{tabular}{|c|c|c|c|c|c|c|}
\hline Expt. & Period & $\begin{array}{l}\text { Urchin } \\
\text { source }\end{array}$ & $\begin{array}{l}\text { Amoeba } \\
\text { source }\end{array}$ & $\begin{array}{l}\text { Culture } \\
\text { age (wk) }\end{array}$ & $\begin{array}{l}\text { Dose } \\
\left(\mathrm{ml}^{-1}\right)\end{array}$ & $\mathrm{n}$ \\
\hline 1 & 24 Nov-12 Dec & SP & SMB (8) & 5 & $600 \pm 90$ & $3-4$ \\
\hline 2 & 12 Feb-14 Mar & GSL & $\begin{array}{c}\text { SMB (8) } \\
\text { SMB (60) } \\
\text { SP (8) } \\
\text { SPS (8) }\end{array}$ & $\begin{array}{l}16.5 \\
12.5 \\
13.5 \\
11.5\end{array}$ & $\begin{array}{l}300 \pm 82 \\
300 \pm 63 \\
300 \pm 45 \\
300 \pm 51\end{array}$ & 10 \\
\hline 3 & 26 Mar-15 May & GSL & $\begin{array}{l}\text { SMB (8) } \\
\text { SP (8) }\end{array}$ & $\begin{array}{l}22.5 \\
19.5\end{array}$ & $\begin{array}{l}333 \pm 49 \\
333 \pm 20\end{array}$ & 10 \\
\hline \multirow{2}{*}{\multicolumn{2}{|c|}{$\begin{array}{l}\text { Jones \& Scheibling (1985) } \\
\text { Jellett \& Scheibling (1988) }\end{array}$}} & NS & NS & ND & $100-300$ & 10 \\
\hline & & NS & NS & 5 & 300 & 5 \\
\hline
\end{tabular}

\section{Water-borne transmission experiment}

To determine whether the temperature-dependent rate of transmission and progression of disease from moribund sea urchins to healthy conspecifics was consistent with paramoebiasis, we conducted a waterborne transmission experiment from 30 September to 16 October 2011, using the same methodology and apparatus as Scheibling \& Stephenson (1984). We recorded time to $\geq 50 \%$ morbidity $\left(t_{50}, \mathrm{~d}\right)$ of sea urchins after exposure to infected conspecifics, for comparison with values from previous water-borne transmission experiments at $16^{\circ} \mathrm{C}$ using sea urchins infected with Paramoeba invadens (Scheibling \& Stephenson 1984, Jellett \& Scheibling 1988b, Scheibling et al. 2010, Feehan et al. 2012). Morbidity was measured as time to loss of attachment, when sea urchins had detached from the sides or bottom of aquaria and could not right themselves within $20 \mathrm{~min}$. Moribund sea urchins were recorded daily and removed from each aquarium. Groups of 20 healthy sea urchins (collected from Splitnose Point on 5 August 2011, prior to the disease outbreak and maintained in flow-through seawater tanks in the laboratory until use) were placed in 2 aquaria supplied with $16^{\circ} \mathrm{C}$ seawater. Sea urchins were visually inspected to ensure that they had no lesions or other abnormalities, and a subset was tested to ensure that they could right themselves within 5 min when inverted. Three moribund sea urchins collected from $8 \mathrm{~m}$ cages in St. Margarets Bay on 29 September (the same source as isolate SMB-8) were placed in a glass 'source' tube that was spliced into the incurrent seawater supply of one aquarium as the diseaseexposed treatment. Three healthy sea urchins (from the same Splitnose Point collection as above) were placed in another tube that supplied the remaining aquarium as the control treatment.

\section{Injection experiments}

To determine whether the temperature-dependent rate of progression of disease in healthy sea urchins injected with cultured amoebae was consistent with paramoebiasis, we conducted an injection experiment using the methods of Jones \& Scheibling (1985) and Jellett \& Scheibling (1988b) (Table 2). As in the water-borne transmission 
experiment, moribund sea urchins were recorded daily and removed from each aquarium. We measured $t_{50}$ of sea urchins following injection with amoebae for comparison with similar experiments conducted in the 1980s (Jones \& Scheibling 1985, Jellett \& Scheibling 1988b, Table 2). Groups of 3 to 4 sea urchins (from the sample collected from Splitnose Point on 5 August) were placed in 6 replicate aquaria with seawater at $16^{\circ} \mathrm{C}$. Sea urchins were visually inspected and a subset was tested to ensure that they could right themselves when inverted. Sea urchins in 3 randomly selected aquaria were injected with $1 \mathrm{ml}$ of monoxenic culture of amoebae (isolate SMB-8) that was treated with antibiotics (10 000 IU penicillin, $10000 \mu \mathrm{g}$ streptomycin) $2 \mathrm{~h}$ prior to injection, as the infection treatment. The inoculum was diluted to a concentration of $\sim 600$ amoebae $\mathrm{ml}^{-1}$, as measured using a haemocytometer. Sea urchins in the remaining 3 aquaria were injected with $1 \mathrm{ml}$ of antibiotictreated Escherichia coli as a control. The control inoculum was diluted to the same concentration of bacterial cells as the inoculum of the infection treatment. Streaks with the injection treatment and control inoculum on marine nutrient agar showed no growth after $24 \mathrm{~h}$ and individual colonies after $1 \mathrm{wk}$ at $18^{\circ} \mathrm{C}$. These colonies were demonstrated to be $E$. coli by replicated direct-sequencing of PCR-amplified partial SSU rDNA sequences (not shown).

To determine whether there are different infective strains of the amoeba along the coast of Nova Scotia, we conducted a second injection experiment to compare the virulence of the 4 isolates: SMB-8, SMB-60, SP and SPS (Table 2). We measured rates of sea urchin morbidity $\left(t_{50}\right)$ following injection with amoebae from the respective sites using an experimental design similar to the first injection experiment. Because all healthy sea urchins from laboratory reserves (sea urchins collected from Splitnose Point on 5 August 2011) had been used in previous experiments, healthy sea urchins for the second injection experiment were obtained from the St. Lawrence estuary, where paramoebiasis has not been observed. Sea urchins were collected on 13 December 2011 by divers at Fisheries and Oceans Canada, Institut Maurice-Lamontagne, Mont Joli, Quebec, and ground-transported in chilled plastic bins to Dalhousie University within $24 \mathrm{~h}$ of collection. Groups of 10 sea urchins were placed in 10 replicate aquaria with $16^{\circ} \mathrm{C}$ seawater. Sea urchins within 2 randomly selected aquaria for each of the 4 sites were injected with $1 \mathrm{ml}$ of antibiotic-treated monoxenic culture of amoebae isolated from moribund urchins from a given site, to generate 4 infection treatments based on site-specific amoeba cultures. Each in- oculum was diluted to a concentration of $\sim 300$ amoebae $\mathrm{ml}^{-1}$. Sea urchins in the remaining 2 aquaria were injected with $1 \mathrm{ml}$ of antibiotic-treated Escherichia coli as a control. The control inoculum was diluted to the same concentration of bacterial cells as the infection treatment (isolate SMB-8) with the greatest concentration (smallest dilution factor), as a conservative measure. Streaks of inocula from the 4 infection treatments and the control on marine nutrient agar showed no growth after $24 \mathrm{~h}$ at $18^{\circ} \mathrm{C}$. The effect of amoeba source (fixed factor, 4 levels: SMB-8, SMB-60, SP, SPS) on $t_{50}$ of sea urchins was analysed using 1-way analysis of variance (ANOVA).

To determine whether the virulence of the amoeba is maintained in culture over time, we conducted a third injection experiment reusing 2 of the amoeba cultures used in the second experiment (SP, SMB-8; Table 2). The experimental design was identical to the second experiment, except that the cultures were $\sim 6$ wk older. The effect of amoeba source (fixed factor, 2 levels: SMB-8, SP) and culture age (fixed factor, 2 levels: $\sim 15 \mathrm{wk}, \sim 21 \mathrm{wk})$ on $t_{50}$ of sea urchins was analysed using 2-way ANOVA.

For each injection experiment, we cultured the radial nerve of 3 to 5 moribund sea urchins in each infection treatment within $24 \mathrm{~h}$ of the onset of signs of paramoebiasis, and in controls at the end of the experiment, to determine whether amoebae were present, using the methods described above.

\section{Light microscopy}

Live cells from the 4 isolates, SMB-8, SMB-60, SPS and SP, were collected from plates using a loop or sterile scraper, and mixed with 5 to $10 \mu$ of sterile seawater on a glass slide. Cells were observed using phase-contrast and differential interference contrast (DIC) light microscopy with 100× magnification objective lenses on a Zeiss Axiovert 200M microscope (Carl Zeiss Canada) fitted with a Zeiss AxioCam HRc camera. Length and width measurements were taken from samples prepared using the protocol outlined by Jones (1985). Briefly, amoebae were taken using the method above from cultures that were 6 to $8 \mathrm{~d}$ old and were then mounted on a Vaseline-supported slide preparation. Photographs were taken using a $40 \times$ objective lens with an additional 1.6x 'optivar' lens in the lightpath, under bright-field optics. The length and width were measured from 30 randomly selected cells per isolate using the AxioVision-V4.6.1.0 software (Carl Zeiss). Differences in length, width and length:width ratio were compared 
using 1-way ANOVA. Pairwise comparisons were conducted using Tukey's test $(\alpha=0.05)$. All statistical tests were run with Statistica 8 (StatSoft). Data for each test satisfied the assumption of homoscedasticity according to Cochran's $C$-test ( $\alpha=0.05)$.

\section{Scanning electron microscopy}

The surfaces of week-old plate cultures of all 4 isolates were scraped using sterile scrapers, and for each, a $50 \mu$ drop of the resulting cell suspension was transferred to the center of a $6 \mathrm{~mm}$ diameter coverslip and left to stand for $20 \mathrm{~min}$ to allow amoebae to attach to the glass. Coverslips were then prepared following a slightly modified version of the protocol of Kudryavtsev et al. (2011). Briefly, the coverslips were fixed by suspension on $125 \mu$ of $1 \%$ osmium tetroxide and $2.5 \%$ glutaraldehyde in seawater (thus the final concentrations of osmium tetroxide and glutaraldehyde were 0.7 and $1.8 \%$ due to dilution by the $50 \mu \mathrm{l}$ of fluid already present on the coverslips). The coverslips were rinsed and then dehydrated using washes of $100 \%$ seawater, $50 \%$ seawater and 2 washes of distilled water followed by approximately $10 \mathrm{~min}$ in each of the following ethanol mixes: 35, 50, 70,90 and $95 \%$ and then 3 washes in $100 \%$ ethanol. The coverslips were critical-point-dried, mounted on stubs, and sputter-coated with a mixture of gold and palladium. The finished coverslips were observed using a Hitachi S-4700 scanning electron microscope (SEM), and photographs were taken of the amoebae, paying attention to the cell surface.

\section{Molecular sequencing}

Genomic DNA was extracted from isolates SMB-8, SMB-60, SPS and SP, using the DNeasy Blood \& Tissue Kit (Qiagen). The nuclear SSU rDNA sequences were amplified by PCR using primers Euk A and Euk B (Medlin et al. 1988) in a $20 \mu$ reaction containing the following final reagent concentrations: $1 \times$ PCR buffer (Life Technologies), $2 \mathrm{mM} \mathrm{MgCl}, 1 \mu \mathrm{m}$ each

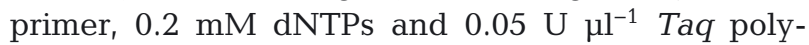
merase. The thermocycling protocol was as follows: $94^{\circ} \mathrm{C}$ for $5 \mathrm{~min}$, then 35 cycles of $94^{\circ} \mathrm{C}$ for $20 \mathrm{~s}, 55^{\circ} \mathrm{C}$ for $2 \mathrm{~min}, 72^{\circ} \mathrm{C}$ for $3 \mathrm{~min}$, then $72^{\circ} \mathrm{C}$ for $10 \mathrm{~min}$. The PCR products were gel-purified using the QIAquick Gel Extraction Kit (Qiagen). The products were directly sequenced in both directions using the amplification primers Euk A and Euk B, plus internal primers 514F (5'-GGT GCC AGC ASC CGC GGT
AA-3'), 536R (5'-GGA ATT ACC GCG GCT GCT GGC A-3'), 1055R (5'-CGG CCA TGC ACC ACC-3') and 1498R (5'-CAC CTA CGG AAA CCT TGT TA-3').

Subsequently, the nuclear SSU rDNA amplicons from 2 isolates, SP and SMB-8, were cloned using the pGEM-T Easy vector system (Promega). Six randomly chosen positive clones from each isolate were grown up overnight in $3 \mathrm{ml} \mathrm{LB}$ medium with $3 \mu \mathrm{l}$ of $100 \mathrm{mg}$ $\mathrm{ml}^{-1}$ ampicillin, and the plasmid DNA was purified using the Qiagen MiniPrep Kit (Qiagen). Following sequencing of all clones using 514F ( 800 bases determined), 2 representative clones from each of the 2 isolates were selected to be completely sequenced in both directions using vector primers and internal sequencing primers 514F, 536R, 1055R and 1055F (5'GGT GGT GCA TGG CCG-3'). The clones selected to be completely sequenced differed in length at a region at which length heterogeneity was suspected, based on direct sequencing of PCR products (see previous paragraph).

To allow an independent examination of the phylogenetic position of Paramoeba invadens and genetic variability amongst strains, parasome SSU rDNA sequences for the SP and SMB-8 isolates were obtained. These were PCR-amplified from the same genomic DNA preparations, using the kinetoplastidspecific primers 'Kineto 14F' and 'Kineto 2026R' (Von der Heyden \& Cavalier-Smith 2005). Other than the primers, the reaction mix was as reported above. The following thermocycling protocol was used: $94^{\circ} \mathrm{C}$ for $5 \mathrm{~min}, 35$ cycles of $94^{\circ} \mathrm{C}$ for $20 \mathrm{~s}, 60^{\circ} \mathrm{C}$ for $2 \mathrm{~min}$ and $72^{\circ} \mathrm{C}$ for $3 \mathrm{~min}$, then $72^{\circ} \mathrm{C}$ for $10 \mathrm{~min}$. The PCR products were cleaned using the QIAquick Gel Extraction Kit and directly sequenced in both directions using Kineto 14F, Kineto 2026R, 514F, 536R, 1055R and 1055F. The new sequences from $P$. invadens were deposited in GenBank under accession numbers KC790384-KC790389.

\section{Sequence analysis}

The 4 complete nuclear SSU rDNA clone sequences from Paramoeba invadens, plus the SSU rDNA sequence from $P$. atlantica (Kudryavtsev et al. 2011) were added to the alignment from Dyková et al. (2011), by eye or using MAFFT v6 (Katoh \& Toh 2008), with the resulting alignment then corrected by eye. The alignment contained 61 sequences, including 53 Paramoeba/Neoparamoeba sequences and 8 other Paramoebidae as outgroups. Three datasets were created from the master alignment; ' $1 \mathrm{~N}$ ' $(61$ sequences; 1597 well-aligned sites) included the out- 
groups, '2N' (53 sequences; 1860 sites) included only Paramoeba/Neoparamoeba, and '3N' (52 sequences; 1986 sites) included all Paramoeba/Neoparamoeba except $P$. atlantica.

A similar process was followed to align the parasome SSU rDNA sequences, with the 2 new sequences from Paramoeba invadens being added to the alignment from Kudryavtsev et al. (2011), using MAFFT v6 with subsequent correction by eye. The final alignment contained 56 sequences including 39 Paramoeba/Neoparamoeba parasome sequences, and 18 other Prokinetoplastida sequences as outgroups. Three datasets were again created: ' $1 \mathrm{P}^{\prime}$ (56 sequences; 1363 well-aligned sites) included outgroups; '2P' (39 sequences; 1502 sites) included only the parasome sequences, and ' $3 \mathrm{P}^{\prime}$ ' (38 sequences; 1576 sites) contained only parasomes, with the $P$. atlantica parasome excluded. Alignments are available from the authors upon request.

Maximum likelihood (ML) trees were estimated for all 6 datasets using RAxML v7.2.8 (Stamatakis 2006). All analyses used the GTR model of nucleotide substitution, with among-site rate variation modelled by a gamma distribution ( $\alpha$ was estimated from the data in each case; $1 \mathrm{~N} \alpha=0.38 ; 2 \mathrm{~N} \alpha=0.21$; $3 \mathrm{~N} \alpha=0.20 ; 1 \mathrm{P} \alpha=0.28$; $2 \mathrm{P} \alpha=0.30$; 3P $\alpha=0.24$ ). In each case, 20 independent searches were run from different random-taxon-addition parsimony starting trees. Support for bipartitions was assessed from 500 bootstrap replicates.

\section{RESULTS}

\section{Laboratory experiments}

In the water-borne transmission experiment, healthy sea urchins exposed to moribund conspecifics from cages at $8 \mathrm{~m}$ depth in St. Margarets Bay were all moribund by Day 12 , and $t_{50}$ was reached after $9 \mathrm{~d}$ (Table 3, Fig. 2). This $t_{50}$ was within the ranges observed in previous water-borne transmission experiments conducted since the early 1980s (Table 3).

In the first injection experiment, which examined whether the temperature-dependent rate of progression of disease in healthy sea urchins injected with cultured amoebae was consistent with paramoebiasis, all but one of the healthy sea urchins injected with amoebae isolated from moribund conspecifics in cages in St. Margarets Bay (isolate SMB-8) were also moribund by Day 15, with a mean $t_{50}$ of $12 \mathrm{~d}$ (Table 3, Fig. 3). Mean $t_{50}$ conformed closely to that observed in similar experiments conducted in the early to mid-1980s.
Table 3. Strongylocentrotus droebachiensis. Waterborne transmission and injection experiments conducted following disease outbreaks since $1980 . t_{50}$ is the time to $\geq 50 \%$ morbidity (exhibiting signs of paramoebiasis, in days) following exposure to 3 to 5 moribund conspecifics. $\mathrm{N}$ is the number of experiments conducted in each year. For all experiments, survival was $100 \%$ in controls. In disease-exposed treatments, survival was $0 \%$ in waterborne transmission experiments and $10 \%$ in injection experiments. For all experiments, water temperature was $16^{\circ} \mathrm{C}$

\begin{tabular}{|c|c|c|c|}
\hline Year(s) & $t_{50}(\mathrm{~d})$ & $\mathrm{N}$ & Source \\
\hline \multicolumn{4}{|c|}{ Waterborne } \\
\hline 2011 & 9 & 1 & This study \\
\hline 2010 & $8-10$ & 3 & Feehan et al. (2012) \\
\hline 2009 & 11 & 1 & Scheibling et al. (2010) \\
\hline 1982 & $12-13.5$ & 7 & $\begin{array}{l}\text { Jellett \& Scheibling } \\
(1988 b)\end{array}$ \\
\hline 1982-83 & $8.5-11.5$ & 7 & $\begin{array}{l}\text { Scheibling \& } \\
\text { Stephenson (1984) }\end{array}$ \\
\hline \multicolumn{4}{|l|}{ Injection } \\
\hline 2011 & 12 & 1 & This study \\
\hline 1982 & 13.5 & 1 & Jellett \& Scheibling (1988b) \\
\hline $1980-83$ & 13 & 1 & Jones \& Scheibling (1985) \\
\hline
\end{tabular}

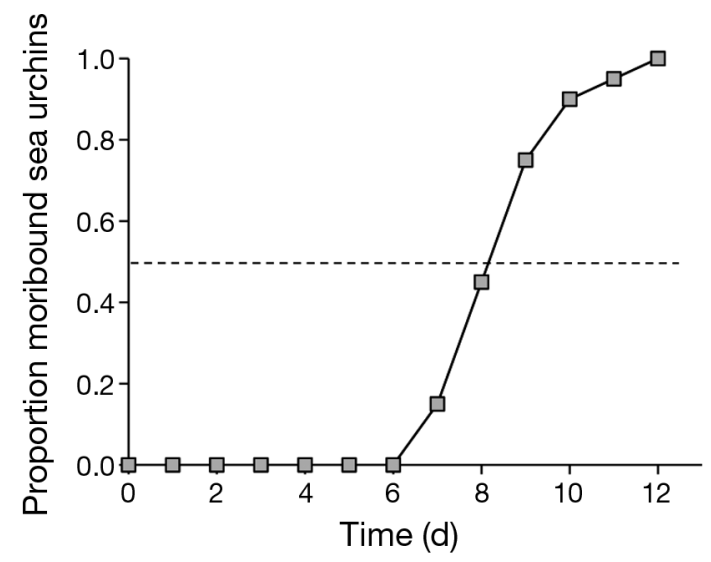

Fig. 2. Strongylocentrotus droebachiensis. Cumulative frequency of morbidity of sea urchins exposed to moribund conspecifics (from cages in St. Margarets Bay) in a waterborne transmission experiment. Dashed line indicates $50 \%$ morbidity. There was no morbidity in controls (not shown). Temperature $=16^{\circ} \mathrm{C}$

In the second injection experiment, which compared the virulence of 4 isolates of amoebae (cultures of Paramoeba invadens from moribund sea urchins collected at different sites: SMB-8, SMB-60, SP and SPS), 1-way ANOVA showed significant differences in $t_{50}$ among the 4 isolate treatments $\left(F_{3,4}=\right.$ $7.73, \mathrm{p}=0.039$; Fig. $4 \mathrm{~A}$ ). In one replicate of the SP treatment, sea urchins only reached $40 \%$ morbidity after $31 \mathrm{~d}$, which was used as a conservative estimate of $t_{50}$ for that replicate in the analysis. The 


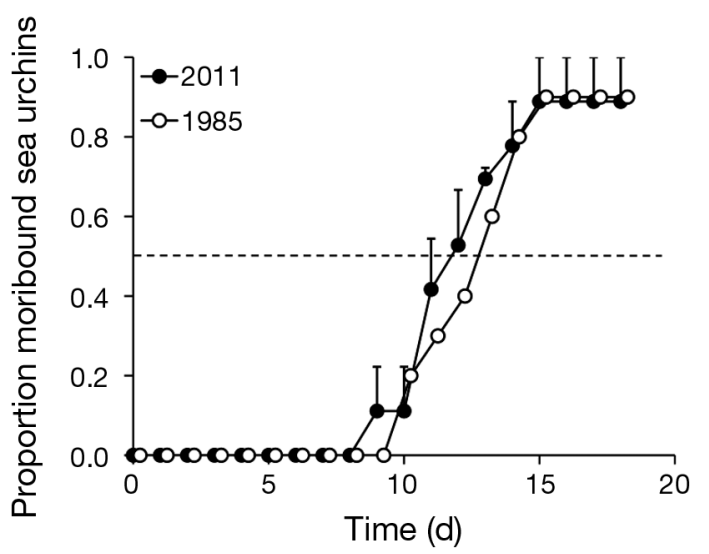

Fig. 3. Strongylocentrotus droebachiensis. Comparison of cumulative frequency of morbidity of sea urchins injected with amoebae isolated from moribund conspecifics collected at $8 \mathrm{~m}$ depth in St. Margarets Bay in 2011 and in a similar experiment conducted by Jones \& Scheibling (1985). Dashed line indicates $50 \%$ morbidity. There was no mortality in controls (not shown) in either experiment. Temperature $=16^{\circ} \mathrm{C}$. Data are mean \pm SE for 3 replicate aquaria. Data from 1985 are offset by $+0.25 \mathrm{~d}$ to avoid overlap of data points between years

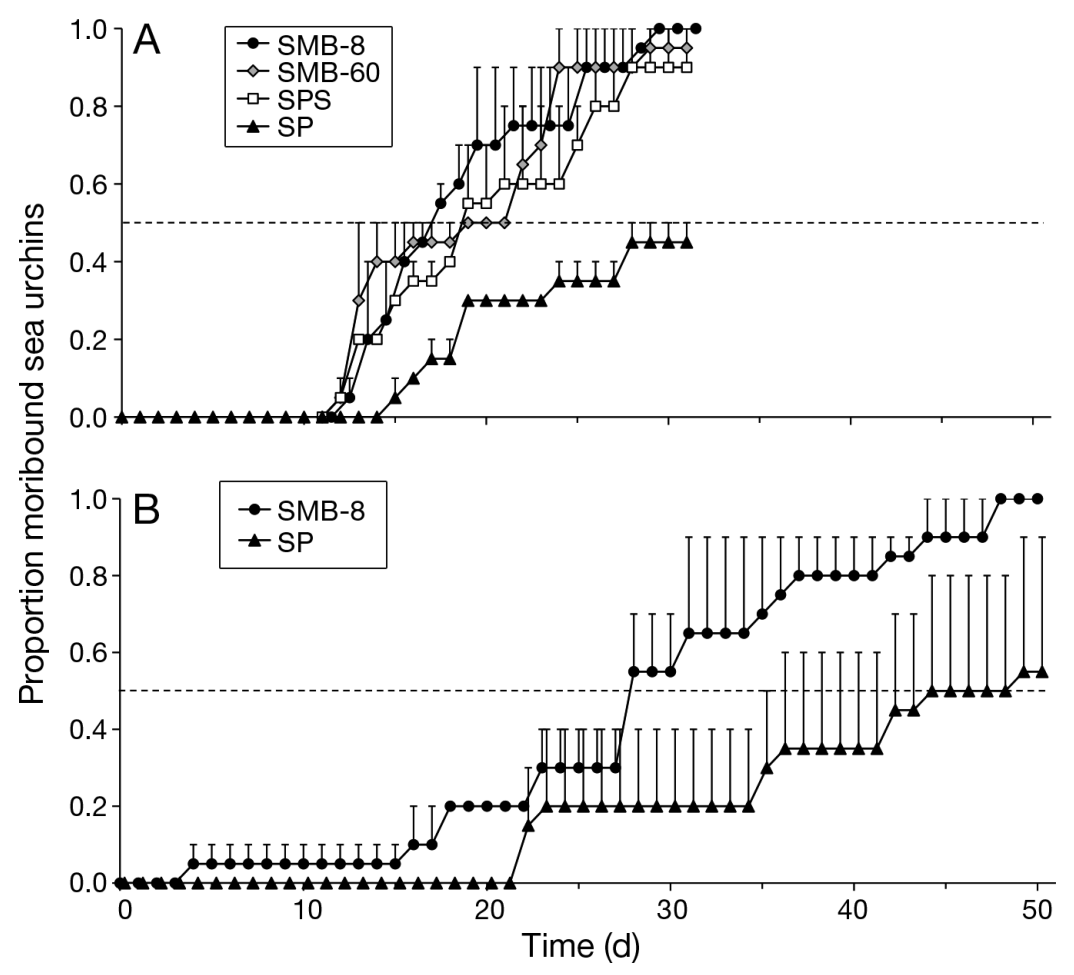

Fig. 4. Strongylocentrotus droebachiensis. Cumulative frequency of morbidity of sea urchins injected with amoebae isolated from (A) moribund conspecifics from 4 sites along the coast of Nova Scotia: St. Margarets Bay at $8 \mathrm{~m}$ (SMB-8) and $60 \mathrm{~m}$ depth (SMB-60), Sandy Point, Shelburne (SPS) and Splitnose Point (SP); and (B) the same cultures for SMB-8 and SP that were 6 wk older. Dashed line indicates $50 \%$ morbidity. There was no morbidity in controls (not shown) in either experiment. Data are mean $\pm \mathrm{SE}$ for 2 replicate aquaria. Data for SMB-8 are offset by $\pm 0.25 \mathrm{~d}$ for clarity estimated mean $t_{50}$ of sea urchins in the SP treatment ( $30 \mathrm{~d}$ ) was greater than the mean $t_{50}$ in SMB-8, SMB-60 and SPS treatments (17 to $19 \mathrm{~d}$ ), meaning that SP was less virulent.

In the third injection experiment, sea urchins were injected with amoebae from 2 of the source treatments used in the second experiment (SMB-8, SP), but when these cultures were $6 \mathrm{wk}$ older. In both cases, $t_{50}$ was about 1.5 times greater than in the second experiment, but the difference between source treatments was consistent between experiments, with SP again producing a larger $t_{50}$ than SMB-8 (Fig. $4 \mathrm{~A}, \mathrm{~B}$ ). The estimated mean $t_{50}$ in the SP treatment was $44 \mathrm{~d}$ in the third experiment, while mean $t_{50}$ in the SMB-8 treatment was $28 \mathrm{~d}$ (Fig. $4 \mathrm{~B}_{\text {; note }}$ that in 1 replicate of the SP treatment, sea urchins only reached $20 \%$ morbidity after $50 \mathrm{~d}$, which we used as a highly conservative estimate of $t_{50}$ for that replicate). A 2-way ANOVA showed significant effects of amoeba source/isolate $\left(F_{1,4}=8.37, \mathrm{p}=\right.$ $0.044)$ and culture age $\left(F_{1,4}=11.32, \mathrm{p}=0.028\right)$, but no interaction between these factors $\left(F_{1,4}=0.09, \mathrm{p}=0.783\right)$.

Paramoeba-like amoebae (Jones 1985) were observed in all cultures of radial nerves of moribund sea urchins taken from the infection treatments of injection experiments. No sea urchins died or showed signs of morbidity in any of the controls of both types of experiments, and amoebae were not observed in cultures of radial nerves of control sea urchins from injection experiments.

\section{Microscopy}

The cell dimensions for the 4 amoebae isolates in culture, estimated from 30 randomly selected cells, are given in Table 4. There was a significant difference in mean width among isolates $\left(F_{3,122}=5.493, \mathrm{p}=0.001\right)$, with SMB-60 having a smaller width than the other 3 isolates $(\mathrm{p}<0.044)$. Mean length also was smallest for SMB-60, although length did not differ significantly among isolates $\left(F_{3,122}=1.975\right.$, $\mathrm{p}=0.121$ ). There was no significant difference in length:width ratio among the 4 isolates $\left(F_{3,122}=1.353\right.$, $\mathrm{p}=0.260$ ). Length and width of all 4 
Table 4. Paramoeba invadens. Dimensions of amoebae. 'Source' is the collection site (in Nova Scotia) of moribund sea urchins from which amoebae were isolated (SMB-8: St. Margarets Bay at 8 m depth; SMB-60: St. Margarets Bay at $60 \mathrm{~m}$ depth; SPS: Sandy Point, Shelburne, $8 \mathrm{~m}$ depth; SP: Splitnose Point, $8 \mathrm{~m}$ depth) or data taken from Jones (1985). ND: no data available

\begin{tabular}{|c|c|c|c|c|c|c|c|}
\hline \multirow[t]{2}{*}{ Source } & \multirow[t]{2}{*}{$\mathrm{n}$} & \multicolumn{2}{|c|}{ Length $(\mu \mathrm{m})$} & \multicolumn{2}{|c|}{ Width $(\mu \mathrm{m})$} & \multicolumn{2}{|c|}{ Length:Width } \\
\hline & & Mean & Range & Mean & Range & Mean & Range \\
\hline SMB-8 & 30 & 23.7 & $9-49$ & 9.3 & $3-19$ & 2.6 & $1-6$ \\
\hline SMB-60 & 30 & 21.8 & $11-31$ & 6.7 & $3-12$ & 3.3 & $2-7$ \\
\hline SPS & 30 & 27.0 & $10-46$ & 10.4 & $3-23$ & 2.6 & $1-6$ \\
\hline SP & 30 & 25.0 & $9-47$ & 9.6 & $4-23$ & 2.6 & $1-9$ \\
\hline Jones (1985) & 308 & 28.3 & $8-57$ & 14.5 & $3-30$ & 2.0 & ND \\
\hline
\end{tabular}
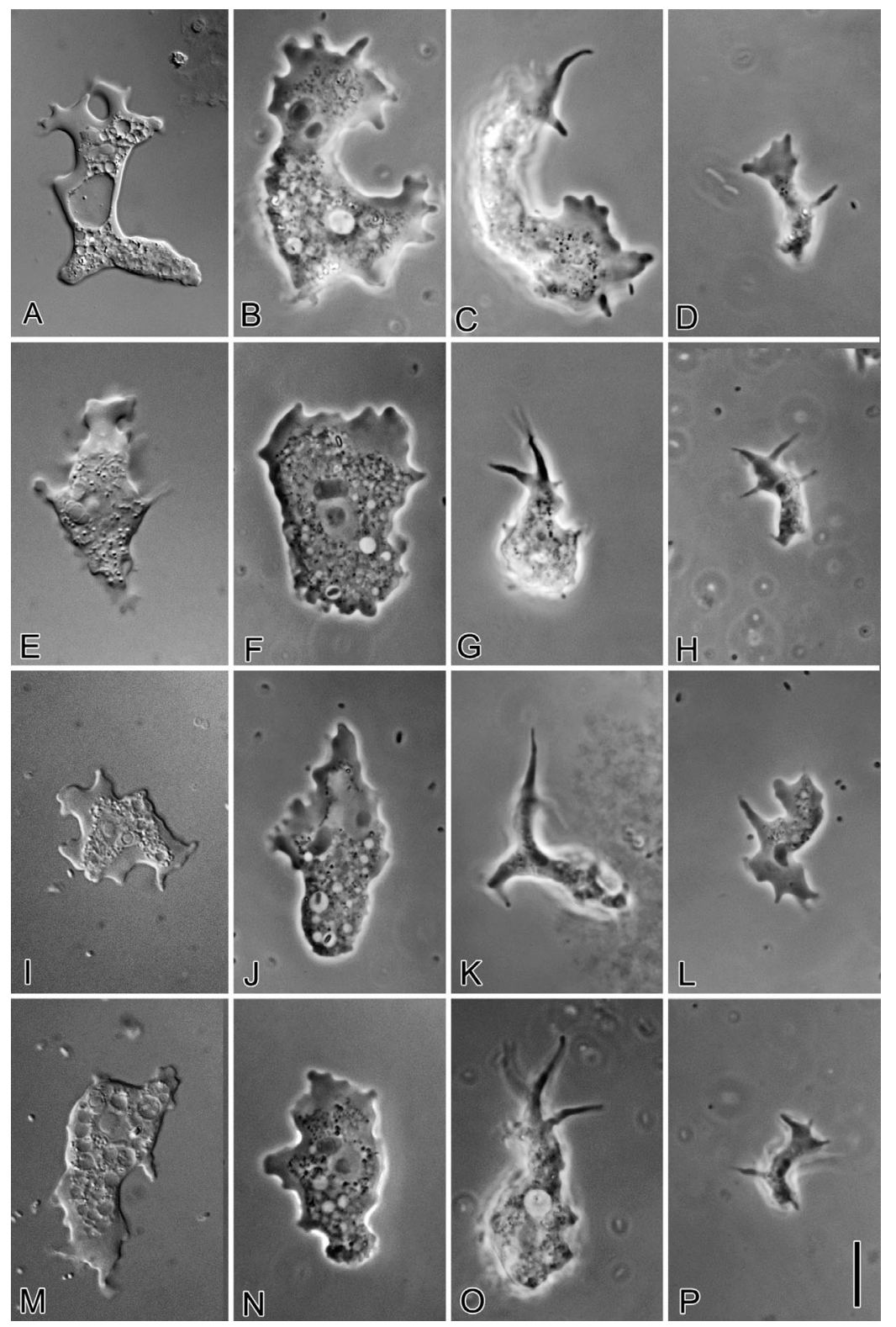

isolates were within the ranges recorded by Jones (1985), and maximum lengths were similar (Table 4). The average width we recorded was somewhat smaller than that recorded by Jones (1985), and the length:width ratio correspondingly higher, but not profoundly so (3.3 for SMB-60, versus 2.0; Table 4). Locomotive forms were elongated in the direction of travel with a large variation in outline (Fig. 5A,E,I,M). Non-locomotive forms were broad and rounder. Both long, narrow pseudopodia and short, broad pseudopodia were regularly observed in all isolates (Fig. 5B, C, F, G, J, K, N,O). One parasome was observed inside each cell. The parasomes were small (approximately $5 \times 2 \mu \mathrm{m}$ ), and pillshaped, with a tripartite form, and were usually located near the nucleus (Fig. 5B,F,J,N). These observations were also in accordance with Jones (1985).

A class of small cells, typically $10 \mu \mathrm{m}$ or less in length, were also observed occasionally in all 4 isolates (Fig. 5D,H, $\mathrm{L}, \mathrm{P})$. These small cells appeared to lack a parasome when viewed by phase contrast or DIC microscopy.

Cells prepared for SEM observation retained the basic morphology seen by light microscopy, with some shrinkage (Fig. 6A,C,E,G). High-resolution micrographs confirmed the lack of microscales on the surface of all 4 isolates (Fig. 6B,D,F,H). The minute particles visible on the surfaces of these amoebae are an order of magnitude smaller than the microscales of Paramoeba spp., and much more sparsely distributed (see Kudryavtsev et al. 2011).

Fig. 5. Paramoeba invadens. Phase contrast and DIC light microscopy, showing morphology of all 4 isolates: (A-D) SMB-8 (see Fig. 4 for site information), (E-H) SMB-60; (I-L) SPS; (M-P) SP. Panels A, E, I, M show the tripartite morphology of the parasome. $\mathrm{B}, \mathrm{F}, \mathrm{J}, \mathrm{N}$ depict the broad, short form of pseudopodia. C, G, K, O show the long, narrow forms of pseudopodia. D, H, L, P show 'small cells'. Scale bar at bottom right represents $10 \mu \mathrm{m}$ for all panels 

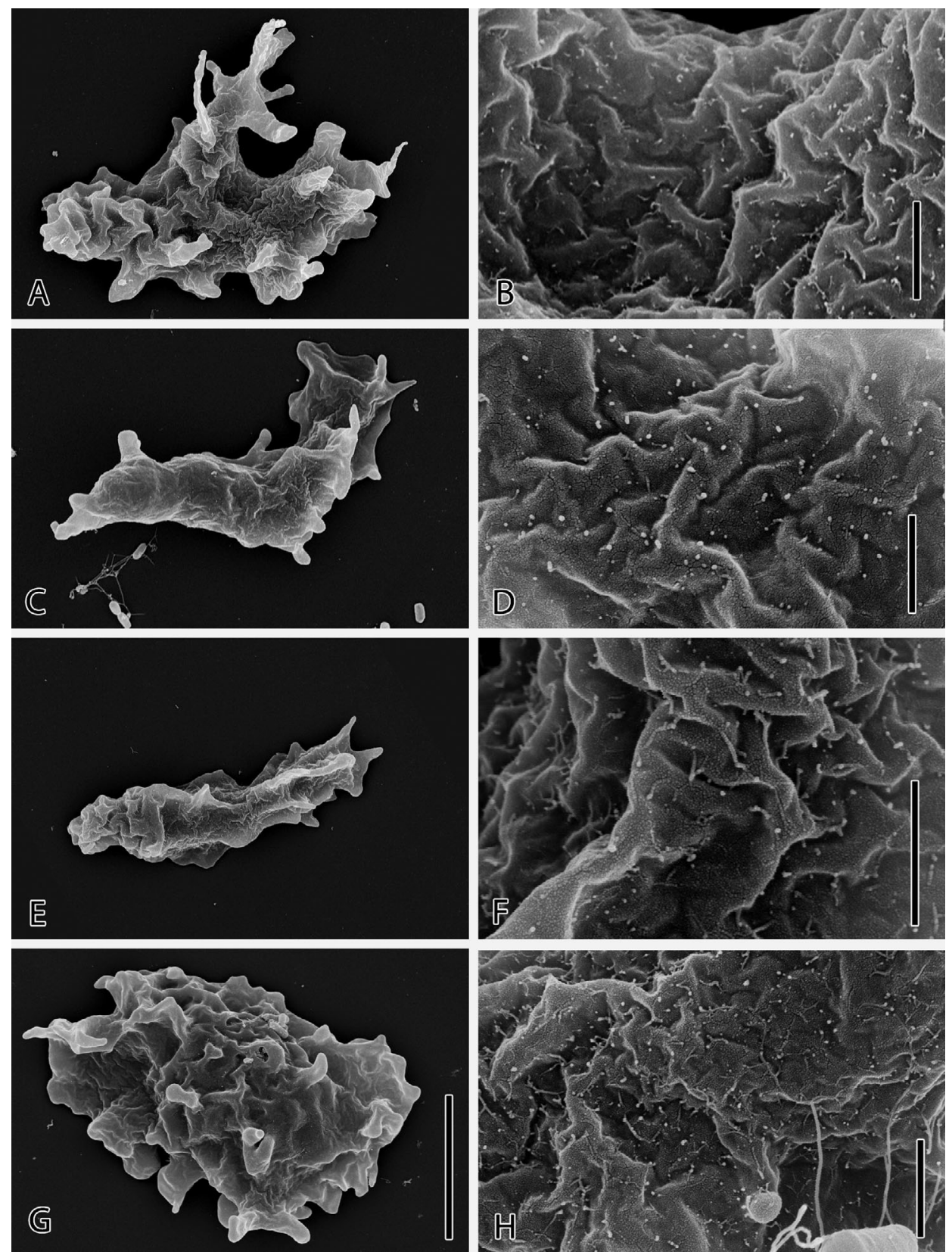

Fig. 6. Paramoeba invadens. Scanning electron micrographs of the 4 studied isolates: (A,B) SMB-8 (see Fig. 4 for site information); $(\mathrm{C}, \mathrm{D})$ SMB-60; (E,F) SPS; $(\mathrm{G}, \mathrm{H})$ SP. Panels A, C, E, G illustrate the variety of general cell shape and pseudopodial forms. $\mathrm{B}, \mathrm{D}, \mathrm{F}, \mathrm{H}$ show the cell surface and absence of microscales. Scale bar in G represents $10 \mu \mathrm{m}$ for A, C, E and G. Scale bars in B,

$$
\text { D, F and } H \text { represent } 1 \mu \mathrm{m}
$$

\section{Gene sequencing and phylogenetic analysis}

No clear differences were seen in the completely sequenced PCR products of the nuclear SSU rDNA between isolates. Several ambiguities were observed that were shared amongst isolates, and there was one region in all 4 isolates that could not be sequenced directly in either direction, suggesting that there was heterogeneity (including length heterogeneity) within isolates, probably among the SSU rDNA copies within a genome. Cloning was then performed from 2 isolates (SMB-8 and SP), and a large number of distinct sequence types observed by partial sequencing. Two representative clones from each isolate were then sequenced completely and used for the phylogenetic analysis. 
Parasome SSU rDNA sequences from the same 2 isolates were sequenced directly from PCR products. No ambiguities were detected in these sequences, and the 2 isolates proved to be identical when compared.

Phylogenetic analysis of nuclear SSU rDNA sequences was initially conducted on dataset ' $1 \mathrm{~N}$ ', with outgroups included (Fig. 7A). Because of the proposed synonymisation of Neoparamoeba with Paramoeba (see 'Discussion'), all species typically assigned to Neoparamoeba are referred to here with both genus names. In the ML tree, $P$. atlantica falls as sister to all other Paramoeba/Neoparamoeba isolates, which form a maximally supported clade (bootstrap support, BS, $100 \%$ ), as in a previous study (Kudryavtsev et al. 2011). P./N. branchiphila forms a distinct clade, as does $P . / N$. perurans, with both receiving $>90 \%$ BS. P./N. pemaquidensis and P./N. aestuarina isolates together form a strongly supported clade (BS $95 \%$ ). Within this assemblage, P./N. aestuarina forms a distinct strongly supported clade (BS 83\%) that emerges from within P./N. pemaquidensis as was also reported by Dyková et al. (2011); however, support for this internal placement is very weak (BS $56 \%$ ). Our new sequences from $P$. invadens appear as a distinct clade that emerges as the sister group to P./N. branchiphila, with strong support (BS 100\%). The P./N. branchiphila plus $P$. invadens clade branches with weak support (BS 51\%) as the sister group to a very weakly supported clade of $P . / N$. perurans plus the sole $P$. eilhardi sequence (BS $45 \%$ ).

The recovered trees are broadly the same in both analyses where the outgroups are excluded (N2 and N3 analyses; Fig. 7B,C). In both analyses, Paramoeba invadens still emerges as the sister group to a robust Paramoeba/Neoparamoeba branchiphila clade, with strong support (BS 80\%, 100\%; Fig. 7B,C). When $P$. atlantica is retained in the analysis (N2 analysis, Fig. 7B) P./N. perurans moves to the 'next deepest' position within the tree, with very weak support (BS $38 \%$ ). $P$. eilhardi moves to branch as a sister group to the $P . / N$. pemaquidensis plus $P . / N$. aestuarina clade, with very weak support (BS $34 \%$ ), and thus remains separate from $P$. atlantica (i.e. not in a clan with $P$. atlantica on an unrooted tree). When $P$. atlantica is also excluded (N3 analysis, Fig. 7C), $P$. eilhardi is sister to the P./N. branchiphila plus $P$. invadens clade, with moderate support (BS $65 \%$ ).

Phylogenetic analysis of the parasome SSU rDNA gene sequences gives broadly similar results to the analyses of nuclear SSU rDNA. In the tree containing all outgroups, Paramoeba atlantica falls as sister to all other Paramoeba/Neoparamoeba species, including
P. invadens (analysis 1P; Fig. 8A). P. invadens branches strongly as sister to the P./N. branchiphila clade (BS $81 \%$ ). However, the single, quite divergent sequence from a $P . / N$. aestuarina parasome branches separately from $P . / N$. pemaquidensis and instead lies as sister to the $P . / N$. branchiphila plus $P$. invadens clade, with $74 \%$ bootstrap support. In the ML tree, $P . / N$. perurans is sister to all other Paramoeba/Neoparamoeba sequences other than $P$. atlantica, with maximal support. There were no reported sequences of $P$. eilhardi parasomes available for comparison.

The relationships amongst the Paramoeba/Neoparamoeba clades differ in both analyses where outgroups are excluded. When $P$. atlantica is retained (analysis 2P; Fig. 8B), the P./N. aestuarina sequence actually falls within the $P$. invadens plus $P . / N$. branchiphila clade as sister to P./N. branchiphila, though with very weak support (BS $46 \%$ ). The $P . / N$. perurans clade falls as sister to these 3 species (BS $67 \%$ ), and P./N. pemaquidensis is deeply diverging. When $P$. atlantica is excluded in addition to the outgroups (analysis 3P; Fig. 8C), a strongly supported relationship between $P$. invadens and P./N. branchiphila is again recovered (BS $83 \%$ ), with $P . / N$. aestuarina forming a clade with $P . / N$. pemaquidensis, with moderate support (BS $67 \%$ ), more similar to the results of the nuclear SSU rDNA analyses (see above).

\section{DISCUSSION}

\section{Validating the identity of Paramoeba invadens as the pathogen of sea urchins in Nova Scotia}

Water-borne disease transmission and injection experiments conducted from 1980 to 2011, culminating in the studies reported here, show a consistent rate of transmission and propagation of paramoebiasis in sea urchins Strongylocentrotus droebachiensis. We also confirm here that the amoebae infecting sea urchins along the coast of Nova Scotia in fall 2011 are morphologically similar to those associated with disease outbreaks in $S$. droebachiensis in the early 1980s, caused by Paramoeba invadens. Together this represents very strong evidence that the pathogen infecting sea urchins in 2011 is indeed P. invadens. Analyses of both nuclear and parasome SSU rDNA show clearly that $P$. invadens is a distinct species (not, for example, a variant of Paramoeba/Neoparamoeba pemaquidensis), that is almost certainly closely related to $P . / N$. branchiphila, a suspected pathogen of sea urchins Diadema aff. antillarum in the Canary Islands, Spain. P./N. branchiphila also has been iso- 
A
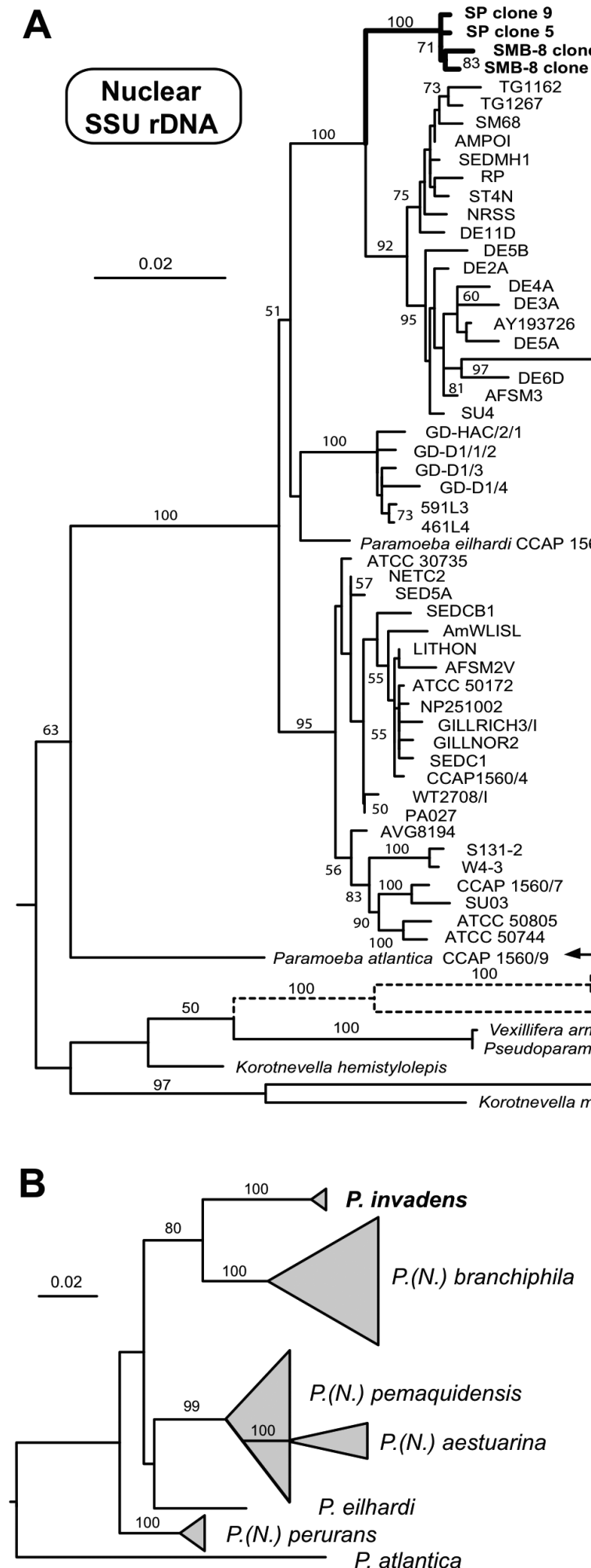

\section{Paramoeba invadens}

Paramoeba

(Neoparamoeba)

branchiphila

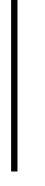

\section{Paramoeba (Neoparamoeba) perurans}

Paramoeba eilhardi

Paramoeba

(Neoparamoeba)

pemaquidensis

Paramoeba

(Neoparamoeba)

aestuarina

Paramoeba atlantica

Outgroups

Fig. 7. Paramoeba/Neoparamoeba spp. Maximum likelihood trees (GTR+gamma model) of selected strains based on SSU rDNA sequences, showing the phylogenetic position of $P$. invadens based on (A) '1N' analysis: 1597 sites, and including all outgroups; (B) '2N' analysis: 1860 sites, and including only Paramoeba/Neoparamoeba; and (C) '3N' analysis: 1986 sites, also excluding $P$. atlantica. Numbers associated with internal branches depict bootstrap support $>50 \%$. Scale bars represent 0.02 expected substitutions per site. Branches depicted with dashed lines indicate a reduction in scale of $50 \%$ 
A

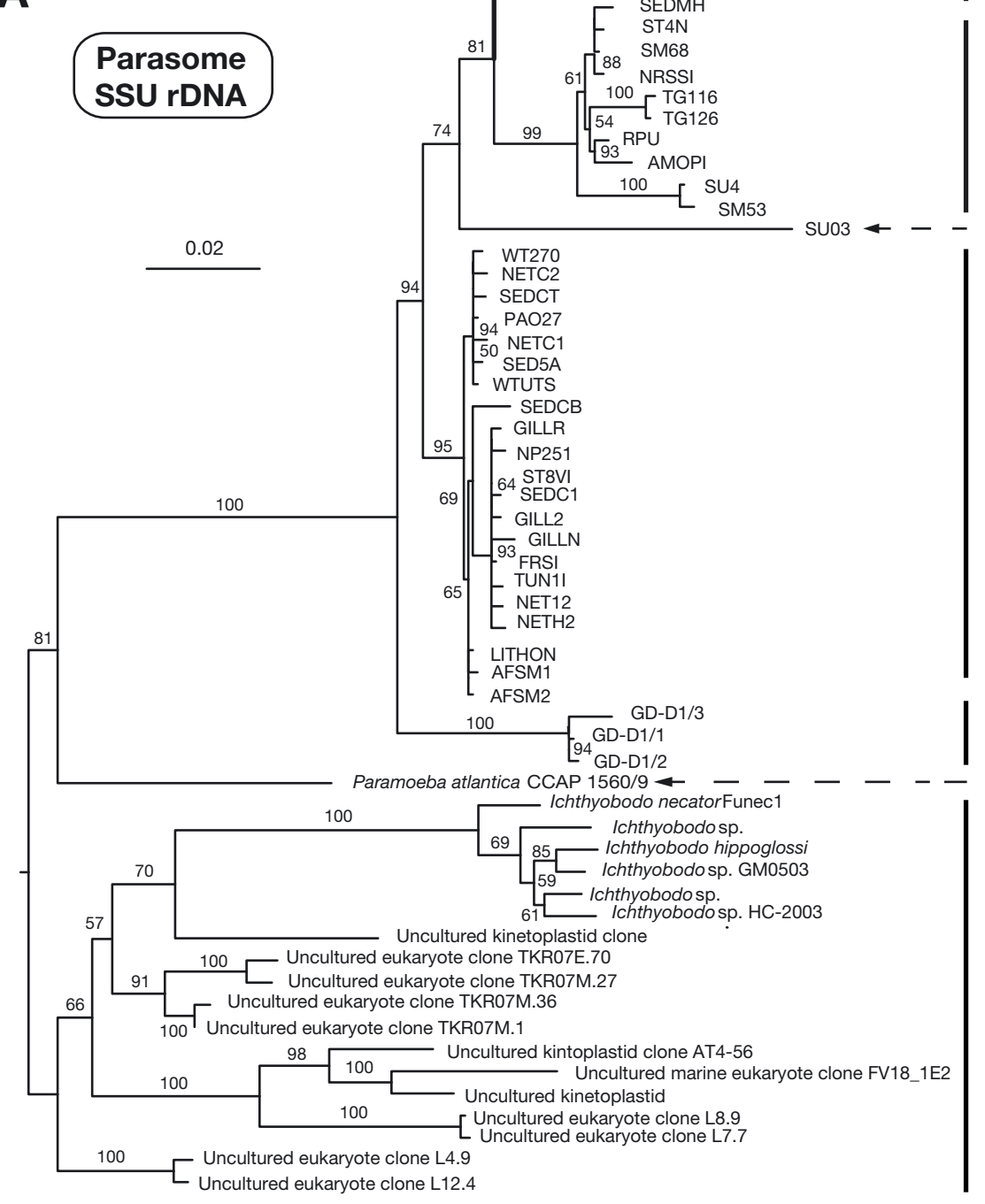

Paramoeba

invadens

\section{Paramoeba}

(Neoparamoeba)

branchiphila

Paramoeba

(Neoparamoeba)

aestuarina

Paramoeba

(Neoparamoeba)

pemaquidensis

\section{Outgroups}

B

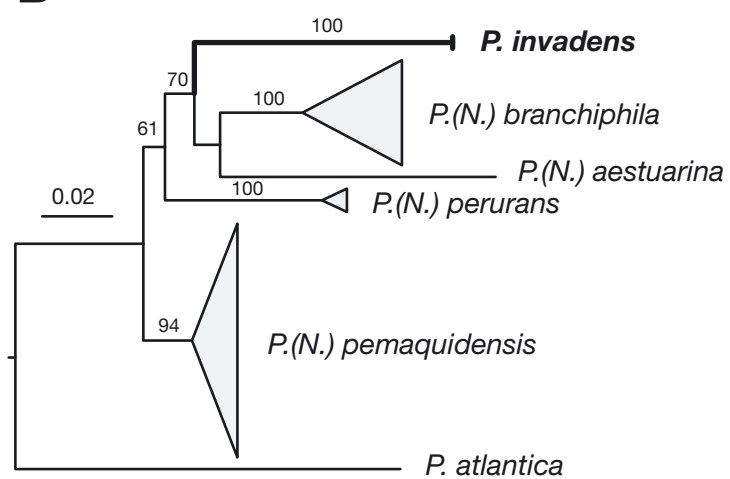

C

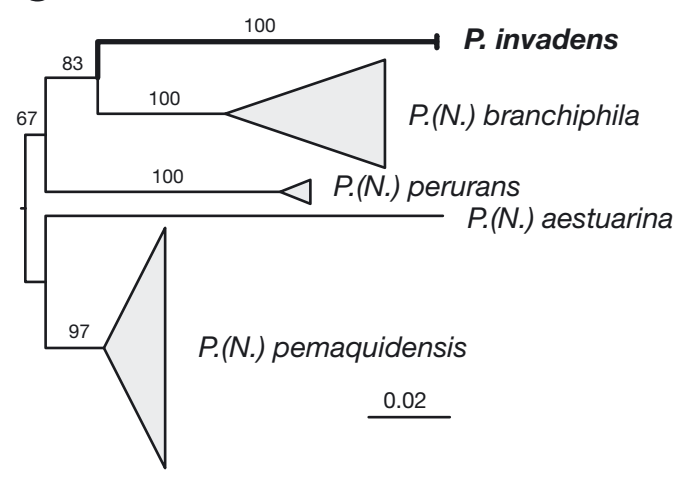

Fig. 8. Paramoeba/Neoparamoeba spp. Maximum likelihood trees (GTR+gamma model) based on parasome SSU rDNA sequences, showing the phylogenetic position of $P$. invadens based on (A) ' $1 \mathrm{P}^{\prime}$ analysis: 1363 sites including all outgroups; (B) '2P' analysis: 1502 sites and including only parasome sequences; and (C) '3P' analysis: 1576 sites and excluding the $P$. atlantica parasome sequence. Numbers associated with internal branches depict bootstrap support $>50 \%$. Scale bars represent 
lated from tissues of crabs in the US, sea urchins in Australia and Greece, and finfish in aquaculture throughout the world (Table 1).

Outbreaks of paramoebiasis in sea urchins along the Atlantic coast of Nova Scotia are associated with hurricanes and tropical storms, and warm sea temperatures (Scheibling \& Lauzon-Guay 2010, Feehan et al. 2012); however, the source of the infective population of Paramoeba invadens remains unknown. The minimum thermal tolerance of $P$. invadens $\left(\sim 2^{\circ} \mathrm{C}\right)$ is above the winter minimum in ocean temperature $\left(0\right.$ to $-2^{\circ} \mathrm{C}$ ) along this coast (Jellett \& Scheibling 1988a). Therefore, it has been considered unlikely that $P$. invadens overwinters in sea urchins or in the surrounding environment (Jellett et al. 1989). Two mechanisms have been postulated to explain recurrent introductions of the pathogen to shallow coastal waters during severe storm events: (1) horizontal advection from distant source populations (Scheibling \& Hennigar 1997) and (2) vertical mixing of amoebae residing in deep sedimentary basins along the Scotian shelf (Scheibling \& Lauzon-Guay 2010), where temperatures rarely fall below $\sim 5^{\circ} \mathrm{C}$ (K. FilbeeDexter \& R. E. Scheibling unpubl. data).

Our analysis of nuclear SSU rDNA showed no fixed genetic differences among Paramoeba invadens isolates derived from moribund sea urchins at 4 sites spanning $\sim 200 \mathrm{~km}$ of coastline (linear distance) and across a depth range of $\sim 50 \mathrm{~m}$. However, injection experiments indicated differences in virulence among cultures of amoebae, with amoebae from one site (SP) having lower virulence than amoebae from the other 3 sites (SMB-8, SMB-60 and SPS). If there were indeed spatial variance in virulence, this would suggest that there is more than one infective subtype of $P$. invadens along the Nova Scotian coast and that the pathogen is introduced at local scales (10s of $\mathrm{km})$, favouring the hypothesis that amoebae reside in nearshore sedimentary basins. It would be interesting to determine whether examining more variable molecular markers (e.g. ITS sequences) would reveal differences among isolates, and if so, whether this molecular difference corresponds to either geographical differences, or differences in virulence.

\section{Global trends in Paramoeba/Neoparamoeba- associated disease events}

Amoebae assigned to the genera Paramoeba and Neoparamoeba have been associated with disease in various marine organisms worldwide (Table 1). However, to our knowledge, Koch's postulates have only been fulfilled for 2 species: $P$. invadens in sea urchins in Nova Scotia (Jones \& Scheibling 1985, this study), and Paramoeba/Neoparamoeba perurans in Atlantic salmon in aquaculture (Crosbie et al. 2012, Table 1). This may reflect the difficulty of culturing these amoebae in the first place (Johnson 1977, Mullen et al. 2004, 2005, Crosbie et al. 2012) or the loss of virulence in culture over time (i.e. reduced infectivity or severity of disease; Jellett \& Scheibling 1988b, Kent et al. 1988, Zilberg et al. 2001).

The results of our successive injection experiments confirm that Paramoeba invadens loses virulence in culture over the scale of weeks. We found a ca. 1.5fold increase in $t_{50}$ of infected Strongylocentrotus droebachiensis between $\sim 15$ and 21 wk old cultures. Jellett \& Scheibling (1988b) also found that virulence of monoxenic cultures of $P$. invadens decreased in sea urchins after $15 \mathrm{wk}$. Other studies have documented changes in metabolism of other Paramoeba/ Neoparamoeba spp. that are associated with a loss of virulence, including a decrease in the number of trophozoites with a fully developed parasome (Dyková et al. 2000), and changes in extracellular products (Kent et al. 1988, Dyková et al. 2000). Villavedra et al. (2007) found that cultured P./N. pemaquidensis has a different antigen profile than freshly isolated $P . / N$. pemaquidensis.

There is evidence that some Paramoeba/Neoparamoeba spp. are opportunistic pathogens, infecting only stressed or diseased individuals. For example, an outbreak of $N$. pemaquidensis in lobster Homarus americanus in Long Island Sound, USA, in 1999 was associated with thermal stress and crowding (Mullen et al. 2004). In the Canary Islands, P./N. branchiphila was isolated from sea urchins Diadema aff. antillarum infected with 'bald sea urchin disease' caused by the bacterium Vibrio sp. (Dyková et al. 2011). In amoebic gill disease (AGD)-infected Atlantic salmon in aquaculture, co-infections with sea lice, bacteria, gelatinous zooplankton, Ichthyobodo (marine costia) and other amoeba species have been observed (Bermingham \& Mulcahy 2006, Nowak et al. 2010, Bustos et al. 2011, Rodger et al. 2011). In our laboratory infection experiments, there was no indication that sea urchins were physiologically stressed: water temperature $\left(16^{\circ} \mathrm{C}\right)$ was well below the maximum thermal tolerance of Strongylocentrotus droebachiensis $\left(22^{\circ} \mathrm{C}\right)$, and no mortality occurred in control sea urchins maintained under the same conditions for $9.5 \mathrm{wk}$. We found no evidence to indicate that a cooccurring pathogen is involved in disease outbreaks in sea urchins in Nova Scotia; however, we cannot disregard the possibility that an undetected and con- 
sistently co-occurring microbe(s) was present in inocula of $P$. invadens used in injection experiments in our study or in previous ones (Jones \& Scheibling 1985, Jellett \& Scheibling 1988b).

It has been suggested that Paramoeba/Neoparamoeba pemaquidensis and P./N. branchiphila were misidentified as the causative agent of AGD in Atlantic salmon Salmo salar (Young et al. 2008). Retrospective analyses of Atlantic salmon gill tissue using in situ probes that hybridize with the SSU rDNA indicate that several cases of AGD previously attributed to P./N. pemaquidensis or P./N. branchiphila were actually caused by $P . / N$. perurans, the proven causative agent of AGD (Young et al. 2008). Crosbie et al. (2012) suggested that current culturing procedures select for non-virulent amoebae species (P./N. branchiphila or P./N. pemaquidensis) instead of $P . / N$. perurans when both are present, leading to misidentification of the actual disease agent and the artificial appearance of rapid loss of virulence. For example, investigators have found that naïve Atlantic salmon develop AGD following water-borne exposure to P./N. pemaquidensis or P./N. branchiphila freshly isolated from the gills of infected conspecifics (Douglas-Helders et al. 2003, Morrison et al. 2005, Vincent et al. 2007); however, AGD is not induced by exposure to cultured P./N. pemaquidensis or P./N. branchiphila (DouglasHelders et al. 2003, Mullen et al. 2004, 2005, Crosbie et al. 2007, 2010a, Vincent et al. 2007). Similarly, Morrison et al. (2005) found that only fresh cultures of P./N. pemaquidensis ( $<72 \mathrm{~h}$ old) induced AGD in naïve Atlantic salmon.

Infections with Paramoeba/Neoparamoeba spp. typically exhibit strong temperature dependence with threshold dynamics. Paramoebiasis in sea urchins off Nova Scotia occurs only above a threshold temperature of $\sim 10^{\circ} \mathrm{C}$, and rates of morbidity of sea urchins increase up to $\sim 20^{\circ} \mathrm{C}$, corresponding to the thermal optimum for growth of $P$. invadens in culture (Scheibling \& Stephenson 1984, Jellett \& Scheibling 1988a). Similarly, infection by Paramoeba/Neoparamoeba of farmed salmonids in Tasmania, Australia (Munday et al. 1990, Clark \& Nowak 1999, DouglasHelders et al. 2001), and blue crab Callinectes sapidus in the northeastern US (Johnson 1977), occurs only above threshold temperatures of $\sim 10$ and $13^{\circ} \mathrm{C}$, respectively. Furthermore, the only documented outbreak of AGD in Atlantic salmon in aquaculture in Norway occurred above a threshold of $\sim 11^{\circ} \mathrm{C}$ and was associated with sea temperatures $\sim 3.5^{\circ} \mathrm{C}$ above the seasonal average (Steinum et al. 2008). Given the temperature dependence of
Paramoeba/Neoparamoeba-associated disease outbreaks, continued ocean warming could have important implications for the resilience of susceptible host populations. Indeed, increases in the frequency and severity of outbreaks of sea urchin paramoebiasis and range of AGD are associated with increasing or unusually high sea temperatures in the affected regions (Steinum et al. 2008, Scheibling \& LauzonGuay 2010).

\section{Systematic and nomenclatural considerations}

Prior to 1987, dactylopodial amoebae with parasomes were assigned to one genus, Paramoeba. Page (1987), however, divided Paramoeba into 2 genera primarily on the presence or absence of surface microscales. The scale-bearing $P$. eilhardi remained in Paramoeba as its type species, while a new genus, Neoparamoeba, was proposed for the species without scales. The organisms originally described as $P$. pemaquidensis and $P$. aestuarina were transferred to Neoparamoeba, as N. pemaquidensis and N. aestuarina, with $N$. pemaquidensis nominated as the type species (Page 1987). Two additional species of Neoparamoeba were described subsequently, viz. $N$. branchiphila (Dyková et al. 2005) and N. perurans (Young et al. 2007), while Kudryavtsev et al. (2011) recently described a new microscale-bearing amoeba as $P$. atlantica. $P$. invadens is anomalous, as it was described shortly before Page (1987) erected the genus Neoparamoeba but was not moved to Neoparamoeba despite positive evidence that it lacked scales (Jones 1985). Probably Page (1987) was unaware of the description.

Page (1987) assigned Paramoeba and Neoparamoeba to different families. Recent SSU rDNA phylogenies, however, show that they are very closely related. In fact $P$. eilhardi, represented by culture CCAP 1560/2, almost always branches in amongst the described Neoparamoeba species, including $N$. pemaquidensis (Dyková et al. 2007, 2008, 2011, Kudryavtsev et al. 2011, this study), while P. atlantica appears as the sister group to all other Paramoeba/ Neoparamoeba (Kudryavtsev et al. 2011, this study). Kudryavtsev et al. (2011) confirmed that culture CCAP 1560/2 has microscales, and that its reported SSU rDNA is correct and not from a contaminant (see Dyková et al. 2007). The most likely interpretation is that Paramoeba as currently circumscribed is paraphyletic, while Neoparamoeba is most likely polyphyletic and represents 2 or more lineages that independently lost microscales (Kudryavtsev et al. 2011). 
Most systematists hold that genera and other taxa should be monophyletic wherever possible. Given the phylogenetic placement of Paramoeba and Neoparamoeba species, in particular their type species, it is likely impossible to subdivide these organisms into 2 monophyletic genera, especially genera that meaningfully reflect the original morphological distinction between Paramoeba and Neoparamoeba (Kudryavtsev et al. 2011). The alternatives are either (1) to treat Paramoeba and Neoparamoeba as a single genus, which by priority would be Paramoeba, (2) to subdivide Paramoeba and probably Neoparamoeba into multiple genera each, or (3) to abandon phylogenetic taxonomy for these organisms. We believe the first option is the most conservative, and would be the least unpopular. Kudryavtsev et al. (2011) already discussed the likelihood that synonymisation of Neoparamoeba with Paramoeba will be required, and it is only because of their commendably very cautious approach to phylogenetic systematics that Paramoeba and Neoparamoeba have not been synonymised already.

Our phylogenetic analyses of nuclear SSU rDNA sequences, with the addition of Paramoeba invadens, return similar results to those of earlier studies (Young et al. 2007, Dyková et al. 2007, 2008, 2011, Kudryavtsev et al. 2011). These analyses do not provide positive evidence to support the existence of separate Paramoeba and Neoparamoeba clades, even (in our analyses) in the absence of outgroups which hypothetically could be affecting the topology recovered for the ingroup (see Fig. 7B), and irrespective of whether $P$. invadens is considered a member of Paramoeba or Neoparamoeba. Notwithstanding the desirability of additional confirming data (Kudryavtsev et al. 2011), to continue to distinguish Paramoeba and Neoparamoeba would simply be delaying the inevitable in our view. Resolving the genus-level taxonomy of Paramoeba and Neoparamoeba now avoids the problem of having to choose between (1) having $P$. invadens assigned to a genus to which it is now clear that it does not fit under rational criteria, or (2) transferring $P$. invadens to Neoparamoeba, thereby adding to the literature an extra name (a novel combination) that is likely to have only a very short active life.

Bearing this in mind, we formally propose that Neoparamoeba be considered a junior synonym of Paramoeba, with Paramoeba to include all dactylopodid amoebae with parasomes, both those with microscales and those that lack them due to secondary loss. Species presently assigned to Paramoeba all remain in this genus, including $P$. invadens (see below). $N$. pemaquidensis and $N$. aestuarina revert to their original names, $P$. pemaquidensis and $P$. aestuarina. Finally, new combinations are proposed for the 2 species originally described as members of Neoparamoeba: N. branchiphila Dykova et al. 2005 and $N$. perurans Young et al. 2007. These species become $P$. branchiphila comb. nov. and $P$. perurans comb. nov. (see below).

\section{Taxonomic summary}

\section{Paramoeba Schaudinn, 1896}

Emended diagnosis: Dactylopodial amoebae with one or more DNA-containing parasomes adjacent or near the nucleus. Surface may be covered with microscales (if absent, these have presumably been lost secondarily).

Included species:

- Paramoeba eilhardi Schaudinn, 1896 (type species)

- Paramoeba aestuarina Page, 1970 [synonym Neoparamoeba aestuarina (Page, 1970) Page, 1987]

- Paramoeba atlantica Kudryavtsev et al., 2011

- Paramoeba branchiphila (Dyková et al., 2005) Feehan et al. comb. nov. [basionym Neoparamoeba branchiphila Dyková et al., 2005]

- Paramoeba invadens Jones, 1985

- Paramoeba pemaquidensis Page, 1970 [synonym Neoparamoeba pemaquidensis (Page, 1970) Page, 1987]

- Paramoeba perniciosa Sprague et al., 1969

- Paramoeba perurans (Young et al., 2007) Feehan et al. comb. nov. [basionym Neoparamoeba perurans Young et al., 2007]

- Paramoeba schaudinni de Faria et al., 1922

Acknowledgements. We thank C. Hopkins for providing sea urchins for experiments, J. Lindley, K. Krumhansl and K. Filbee-Dexter for field assistance, F. Francis for assistance with laboratory experiments and A. A. Heiss for assistance with SEM and phylogenetic analyses. We thank M. Kostka and A. Kudryavtsev for supplying SSU rDNA seed alignments. This research was funded by a Discovery Grant to R.E.S. from the Natural Sciences and Engineering Research Council (NSERC) of Canada, and by support from the Canadian Institute for Advanced Research (CIfAR) and an NSERC discovery grant to A.G.B.S. C.J.F. was supported by a Dalhousie Research Scholarship.

\section{LITERATURE CITED}

Adams MB, Villavedra M, Nowak BF (2008) An opportunistic detection of amoebic gill disease in blue warehou, Seriolella brama Günther, collected from an Atlantic 
salmon, Salmo salar L., production cage in south eastern Australia. J Fish Dis 31:713-717

> Bermingham ML, Mulcahy MF (2006) Microfauna associated with amoebic gill disease in sea-farmed Atlantic salmon, Salmo salar L., smolts. J Fish Dis 29:455-465

Brady SM, Scheibling RE (2005) Repopulation of the shallow subtidal zone by green sea urchins (Strongylocentrotus droebachiensis) following mass mortality in Nova Scotia, Canada. J Mar Biol Assoc UK 85:1511-1517

Bridle AR, Crosbie PBB, Cadoret K, Nowak BF (2010) Rapid detection and quantification of Neoparamoeba perurans in the marine environment. Aquaculture 309:56-61

> Bustos PA, Young ND, Rozas MA, Bohle HM, Ildefonso RS, Morrison RN, Nowak BF (2011) Amoebic gill disease (AGD) in Atlantic salmon (Salmo salar) farmed in Chile. Aquaculture 310:281-288

> Caraguel CG, O'Kelly CJ, Legendre P, Frasca S and others (2007) Microheterogeneity and coevolution: an examination of rDNA sequence characteristics in Neoparamoeba pemaquidensis and its prokinetoplastid endosymbiont. J Eukaryot Microbiol 54:418-426

> Clark A, Nowak BF (1999) Field investigations of amoebic gill disease in Atlantic salmon, Salmo salar L., in Tasmania. J Fish Dis 22:433-443

Crosbie PBB, Adams MB, Attard MGG, Nowak BF (2007) Development of an in vivo assay to assess attachment of Neoparamoeba sp. (an amphizoic gymnamoeba) to the gills of Atlantic salmon, Salmo salar L. J Fish Dis 30: 187-190

Crosbie PBB, Bridle AR, Leef MJ, Nowak BF (2010a) Effects of different batches of Neoparamoeba perurans and fish stocking densities on the severity of amoebic gill disease in experimental infection of Atlantic salmon, Salmo salar L. Aquacult Res 41:505-516

Crosbie PBB, Ogawa K, Nakano D, Nowak BF (2010b) Amoebic gill disease in hatchery-reared ayu, Plecoglossus altivelis (Temminck \& Schlegel) in Japan caused by Neoparamoeba perurans. J Fish Dis 33:455-458

Crosbie PBB, Bridle AR, Cadoret K, Nowak BF (2012) In vitro cultured Neoparamoeba perurans causes amoebic gill disease in Atlantic salmon and fulfils Koch's postulates. Int J Parasitol 42:511-515

Douglas-Helders M, Saksida S, Raverty S, Nowak BF (2001) Temperature as a risk factor for outbreaks of Amoebic Gill Disease in farmed Atlantic salmon (Salmo salar). Bull Eur Assoc Fish Pathol 21:114-116

> Douglas-Helders GM, Dawson DR, Carson J, Nowak BF (2002) Wild fish are not a significant reservoir for Neoparamoeba pemaquidensis (Page, 1987). J Fish Dis 25: 569-574

> Douglas-Helders GM, Tan C, Carson J, Nowak BF (2003) Effects of copper-based antifouling treatment on the presence of Neoparamoeba pemaquidensis Page, 1987 on nets and gills of reared Atlantic salmon (Salmo salar). Aquaculture 221:13-22

Dyková I, Novoa B (2001) Comments on diagnosis of amoebic gill disease (AGD) in turbot, Scophthalmus maximus. Bull Eur Assoc Fish Pathol 21:40-44

- Dyková I, Figueras A, Novoa B, Casal JF (1998) Paramoeba sp., an agent of amoebic gill disease of turbot Scophthalmus maximus. Dis Aquat Org 33:137-141

Dyková I, Figueras A, Peric Z (2000) Neoparamoeba Page, 1987: light and electron microscopic observations on six strains of different origin. Dis Aquat Org 43:217-223

Dyková I, Nowak BF, Crosbie PBB, Fiala I and others (2005)
Neoparamoeba branchiphila n. sp., and related species of the genus Neoparamoeba Page, 1987: morphological and molecular characterization of selected strains. J Fish Dis 28:49-64

Dyková I, Nowak B, Pecková H, Fiala I, Crosbie P, Dvoráková H (2007) Phylogeny of Neoparamoeba strains isolated from marine fish and invertebrates as inferred from SSU rDNA sequences. Dis Aquat Org 74:57-65

> Dyková I, Fiala I, Pecková H (2008) Neoparamoeba spp. and their eukaryotic endosymbionts similar to Perkinsela amoebae (Hollande, 1980): coevolution demonstrated by SSU rRNA gene phylogenies. Eur J Protistol 44:269-277

> Dyková I, Lorenzo-Morales J, Kostka M, Valladares B, Pecková H (2011) Neoparamoeba branchiphila infections in moribund sea urchins Diadema aff. antillarum in Tenerife, Canary Islands, Spain. Dis Aquat Org 95:225-231

Feehan C, Scheibling RE, Lauzon-Guay JS (2012) An outbreak of sea urchin disease associated with a recent hurricane: support for the 'killer storm hypothesis' on a local scale. J Exp Mar Biol Ecol 413:159-168

Fiala I, Dyková I (2003) Molecular characterisation of Neoparamoeba strains isolated from gills of Scophthalmus maximus. Dis Aquat Org 55:11-16

> Harvell D, Jordan-Dahlgren E, Merkel S, Rosenberg E and others (2007) Coral disease, environmental drivers, and the balance between coral and microbial associates. Oceanography 20:172-195

$>$ Jellett JF, Scheibling RE (1988a) Effect of temperature and prey availability on the growth of Paramoeba invadens in monoxenic culture. Appl Environ Microbiol 54:1848-1854

Jellett JF, Scheibling RE (1988b) Virulence of Paramoeba invadens Jones (Amoebida, Paramoebida) from monoxenic and polyxenic culture. J Protozool 35:422-424

Jellet JF, Scheibling RE, Wardlaw AC (1988) Host specificity of Paramoeba invadens, a sea urchin pathogen. In: Burke RD, Mladenov PV, Lambert P, Parsley RL (eds) Echinoderm biology. Balkema, Rotterdam, p 755-761

Jellett JF, Novitsky JA, Cantley JA, Scheibling RE (1989) Non-occurrence of free-living Paramoeba invadens in water and sediments of Halifax Harbour, Nova Scotia, Canada. Mar Ecol Prog Ser 56:205-209

> Johnson PT (1977) Paramoebiasis in the blue crab, Callinectes sapidus. J Invertebr Pathol 29:308-320

Jones GM (1985) Paramoeba invadens n. sp. (Amoebidae, Paramoebidae) a pathogenic amoeba from the sea urchin, Strongylocentrotus droebachiensis, in eastern Canada. J Protozool 32:346-369

Jones GM, Scheibling RE (1985) Paramoeba sp. (Amoebida, Paramoebidae) as the possible causative agent of sea urchin mass mortality in Nova Scotia. J Parasitol 71: 559-565

Jones GM, Scheibling RE, Hebda AJ, Miller RJ (1985) Amoebae in tissues of diseased echinoids (Strongylocentrotus droebachiensis) in Nova Scotia. In: Keegan BF, O'Connor BDS (eds) Echinodermata: Proc Int Echinoderms Conf, Galway, 24-29 September 1984. AA Balkema, Rotterdam, p 289-293

Katoh K, Toh H (2008) Recent developments in the MAFFT multiple sequence alignment program. Brief Bioinf 9: 286-298

Kent ML, Sawyer TK, Hedrick RP (1988) Paramoeba pemaquidensis (Sarcomastigophora: Paramoebidae) infestation of the gills of coho salmon Oncorhynchus kisutch reared in seawater. Dis Aquat Org 5:163-169 
Kudryavtsev A, Pawlowski J, Hausmann K (2011) Description of Paramoeba atlantica n. sp. (Amoebozoa, Dactylopodida) - a marine amoeba from the eastern Atlantic, with emendation of the dactylopodid families. Acta Protozool 50:239-253

Lessios HA (1988) Mass mortality of Diadema antillarum in the Caribbean: What have we learned? Annu Rev Ecol Syst 19:371-393

Medlin L, Elwood HJ, Stickel S, Sogin ML (1988) The characterization of enzymatically amplified eukaryotic 16Slike rDNA-coding regions. Gene 71:491-499

Messick GA (2002) A survey for prevalence of Paramoeba spp. in blue crabs along the Atlantic and Gulf coasts. Proc Annu Conf Southeast Assoc Fish and Wildl Agencies 56:105-113

Miller RJ (1985) Succession in sea urchin and seaweed abundance in Nova Scotia, Canada. Mar Biol 84:275-286

> Morrison RN, Crosbie PBB, Cook MT, Adams MB, Nowak BF (2005) Cultured gill-derived Neoparamoeba pemaquidensis fails to elicit amoebic gill disease (AGD) in Atlantic salmon Salmo salar. Dis Aquat Org 66: 135-144

Mullen TE, Russell S, Tucker MT, Maratea JL and others (2004) Paramoebiasis associated with mass mortality of American lobster Homarus americanus in Long Island Sound, USA. J Aquat Anim Health 16:29-38

Mullen TE, Nevis KR, O'Kelly CJ, Gast RJ, Frasca S (2005) Nuclear small-subunit ribosomal RNA gene-based characterization, molecular phylogeny and PCR detection of the Neoparamoeba from western Long Island Sound lobster. J Shellfish Res 24:719-731

Munday BL, Foster CK, Roubal FR, Lester RGL (1990) Paramoebic gill infection and associated pathology of Atlantic salmon, Salmo salar, and rainbow trout, Salmo gairdneri, in Tasmania. In: Perkins FO, Cheng TC (eds) Pathology in marine science. Academic Press, San Diego, CA, p 215-222

> Nowak BF, Bryan J, Jones SRM (2010) Do salmon lice, Lepeoptheirus salmonis, have a role in the epidemiology of amoebic gill disease caused by Neoparamoeba perurans? J Fish Dis 33:683-687

Page FC (1970) Two new species of Paramoeba from Maine. J Protozool 17:421-427

Page FC (1987) The classification of naked Amoebae (Phylum Rhizopoda). Arch Protistenkd 133:199-217

> Rodger HD, Murphy K, Mitchell SO, Henry L (2011) Gill disease in marine farmed Atlantic salmon at four farms in Ireland. Vet Rec 168:668

Roubal FR, Lester RJG, Foster CK (1989) Studies on cultured and gill attached Paramoeba sp. (Gymnamoeba: Paramoebidae) and the cytopathology of paramoebic gill disease in Atlantic salmon, Salmo salar L., from Tasmania. J Fish Dis 12:481-492

Scheibling RE (1984) Echinoids, epizootics and ecological stability in the rocky subtidal off Nova Scotia, Canada. Helgol Wiss Meeresunters 37:233-242

Scheibling RE (1986) Increased macroalgal abundance following mass mortalities of sea urchins (Strongylocentrotus droebachiensis) along the Atlantic coast of Nova Scotia. Oecologia 68:186-198

Scheibling RE (1988) Microbial control of sea urchins: Achilles' heel or Pandora's box? In: Burke RD, Mladenov PV, Lambert P, Parsley RL (eds) Proc 6th Int Echinoderms
Conf, Victoria, BC, 22-28 Aug, 1987. Balkema, Rotterdam, p 745-754

Scheibling RE, Hennigar AW (1997) Recurrent outbreaks of disease in sea urchins Strongylocentrotus droebachiensis in Nova Scotia: evidence for a link with large-scale meteorologic and oceanographic events. Mar Ecol Prog Ser 152:155-165

- Scheibling RE, Lauzon-Guay JS (2010) Killer storms: North Atlantic hurricanes and disease outbreaks in sea urchins. Limnol Oceanogr 55:2331-2338

Scheibling RE, Stephenson RL (1984) Mass mortality of Strongylocentrotus droebachiensis (Echinodermata: Echinoidea) off Nova Scotia, Canada. Mar Biol 78: 153-164

> Scheibling RE, Feehan C, Lauzon-Guay JS (2010) Disease outbreaks associated with recent hurricanes cause mass mortality of sea urchins in Nova Scotia. Mar Ecol Prog Ser 408:109-116

Senapin S, Phewsaiya K, Briggs M, Flegel TW (2007) Outbreaks of infectious myonecrosis virus (IMNV) in Indonesia confirmed by genome sequencing and use of an alternative RT-PCR detection method. Aquaculture 266:32-38

Sprague V, Beckett RL, Sawyer TK (1969) A new species of Paramoeba (Amoebida, Paramoebidae) parasitic in the crab Callinectes sapidus. J Invertebr Pathol 14:167-174

Stamatakis A (2006) RAxML-VI-HPC: maximum likelihoodbased phylogenetic analysis with thousands of taxa and mixed models. Bioinformatics 22:2688-2690

Steinum T, Kvellestad A, Rønneberg LB, Nilsen H and others (2008) First cases of amoebic gill disease (AGD) in Norwegian seawater farmed Atlantic salmon, Salmo salar L., and phylogeny of the causative amoeba using 18S cDNA sequences. J Fish Dis 31:205-214

> Villavedra M, Lemke S, To J, Broady K, Wallach M, Raison RL (2007) Carbohydrate epitopes are immunodominant at the surface of infectious Neoparamoeba spp. J Fish Dis 30:191-199

Vincent BN, Adams MB, Crosbie PBB, Nowak BF, Morrison RN (2007) Atlantic salmon (Salmo salar L.) exposed to cultured gill-derived Neoparamoeba branchiphila fail to develop amoebic gill disease (AGD). Bull Eur Assoc Fish Pathol 27:112

Von der Heyden S, Cavalier-Smith T (2005) Culturing and environmental DNA sequencing uncover hidden kinetoplastid biodiversity and a major marine clade within ancestrally freshwater Neobodo designis. Int J Syst Evol Microbiol 55:2605-2621

Wong FYK, Carson J, Elliott NG (2004) 18S ribosomal DNAbased PCR identification of Neoparamoeba pemaquidensis, the agent of amoebic gill disease in sea-farmed salmonids. Dis Aquat Org 60:65-76

$>$ Young ND, Crosbie PBB, Adams MB, Nowak BF, Morrison RN (2007) Neoparamoeba perurans n. sp., an agent of amoebic gill disease of Atlantic salmon (Salmo salar L.). Int J Parasitol 37:1469-1481

Young ND, Dyková I, Snekvik K, Nowak BF, Morrison RN (2008) Neoparamoeba perurans is a cosmopolitan aetiological agent of amoebic gill disease. Dis Aquat Org 78: $217-223$

> Zilberg D, Gross A, Munday BL (2001) Production of salmonid amoebic gill disease by exposure to Paramoeba sp. harvested from the gills of infected fish. J Fish Dis 24:79-82 